\title{
LA GOBERNACIÓN DEL REINO DE MALLORCA
}

\author{
Pau CATEURA BENNASSER \\ Universidad de las Islas Baleares
}

\section{INTRODUCCIÓN}

Jaume I anota en su crónica que en octubre de 1230 decide nombrar como lugarteniente de Mallorca a Bernat de Santa Eugènia. Su cometido era someter los últimos focos de resistencia musulmana y proceder como lo hubiera hecho el rey de estar presente. Este carácter militar y de "vices" o poder vicarial constituyen la base constitucional de este cargo, que a lo largo de la Edad Media adquirirá diferentes denominaciones, desde la mencionada de lugarteniente, a la de gobernador, en tiempos de Pedro el Ceremonioso, y lugarteniente general en la segunda mitad del siglo XV. En casos puntuales, como a fines del siglo XIV, después de los tumultos del asalto al call, y a principios del siglo XVI, en el clima previo a la Germanía, el rey optará por el nombramiento de virreyes, con poderes reforzados.

Pero la evolución del cargo, desde sus prerrogativas hasta su eficacia en la acción de gobierno, dependen de la relación de poder entre la monarquía y los poderes locales. En el caso de Mallorca estos últimos se reducen a poderes supramunicipales como el Consell General o el Sindicat de Fora, dado que el reino carece de Cortes propias y carece de ellas, no por casualidad, sino por expresa voluntad de los poderes políticos de instrumentalizar en beneficio propio la debilidad del reino. No olvidemos que el reino de Mallorca, después de la conquista de 1229-1230, fue ocupado y reocupado en tres ocasiones, por Alfonso III, en 1285; por Jaime II de Mallorca, en 1298; y en 1343, por Pedro el Ceremonioso. Cada uno de estos sucesos comportó políticas de subordinación de las instituciones locales, hasta el punto de convertir a los jurados, durante algún tiempo, en una especie de funcionarios remunerados. El cuerpo de privilegios del reino, de índole municipal, apenas suponen más que un velo, que no valla, ante la acción de la monarquía y de sus agentes. 
De las afirmaciones anteriores puede desprenderse la conclusión, sin duda precipitada, de que la acción de gobierno de lugartenientes y gobernadores, fue siempre tarea sencilla. Desde luego es cierto en lo que atañe a barreras jurídicas o institucionales, pero menos cierto si consideramos la intrincada red de los intereses sociales -intereses campesinos versus ciudadanos - y banderías urbanas, cuya floración se produce a partir de fines del siglo XIV. Este mismo esquema, a escala menor, se produce en Menorca e Ibiza. A la tradicional adscripción de los hombres de la época por lo corporativo, se añade en caso del reino Mallorca el de las banderías con marchamo insular.

\section{LUGARTENIENTES, GOBERNADORES Y VIRREYES}

Cuando en 1230, Jaume I nombra al mencionado Bernat de Santa Eugènia como lugarteniente real, el rey está sentando algunos precedentes. En primer lugar, el de su origen, ya que su procedencia era catalana. En segundo lugar, establece un precedente políticamente peligroso, ya que el recién nombrado lugarteniente posee un importante señorío en Mallorca. En cualquier caso dicho nombramiento tiene el sello de lo coyuntural y de lo extraordinario, debido a las circunstancias de la conquista. A partir de entonces, cuando al año siguiente Bernat de Santa Eugenia le presenta su dimisión al rey, éste despliega una política de equilibrios. En lugar de nombrar otro lugarteniente de origen catalán, opta por nombrar un aragonés, Assalit de Gúdar.

Este sistema de alternancia fue interrumpido bruscamente cuando, en el mismo 1231, Jaime I concambió el reino de Mallorca con el condado de Urgel, del que había resultado titular el infante Pedro de Portugal. Assalit de Gúdar no llegó a concluir el año de mandato, ya que el mencionado infante pasa a gobernar la isla en calidad de señor de la misma (Majoricarum dominus). El reino de Mallorca, convertido en señorío, pasa a tener una administración diferenciada. No ha lugar al nombramiento de lugarteniente ya que Pedro de Portugal reside en la isla y sólo de forma esporádica se desplaza a la Península. Sólo entonces designa lugarteniente en su lugar. Otra cuestión es Ibiza, conquistada en 1235, en la que Pedro de Portugal se hace representar por un lugarteniente.

Este esquema administrativo de funcionamiento se mantuvo hasta el año 1244, cuando el rey y el aludido infante proceden a un nuevo concambio. Es entonces, cuando el monarca recupera el control del archipiélago, el momento de una nueva reorganización administrativa. En primer lugar era necesaria la reestructuración del patrimonio real, formado por tres secciones, el realengo, tal como fue establecido en el Llibre del Repartiment, la porción segregada a favor del infante Pedro de Portugal, y la porción del noble Nuño Sans, adquirida a sus albaceas en 1241. Esta tarea así como la de evaluar los compromisos de pago de la bailía de Mallorca fue encomendada a un equipo de aragoneses. A Assalit de Gúdar, como lugarteniente, y a Blasco de Sinos, como batlle.

Las razones del nombramiento de un equipo de aragoneses para las tareas indicadas, pudo obedecer a varias razones. No es la menor el hecho de que poco más de 
seis meses antes del nombramiento, Assalit vendiera al rey una alquería en el reino de Valencia. Que los emolumentos del cargo de lugarteniente formaran parte del pago de dicha transacción parece verosímil. Por otra parte, la designación de Assalit tenía el sello de la reposición, pues su primer mandato - entre mediados de 1231 y el primer trimestre del año siguiente- se había visto truncado por el primer concambio entre el rey y Pedro de Portugal. Finalmente, cabe considerar que la ausencia de vínculos o intereses de Assalit en las islas fuera un factor favorable añadido a los objetivos diseñados por la Corona.

La titulación adoptada por los lugartenientes durante este período fue la de gerentes locum domini Jacobi, Dei gratia, regis Aragonum et regni Maioricarum...in Maioricis'. A través de las primeras cuentas de la bailía de Mallorca, de 1244-1245, conocemos algunos pormenores del cargo. A lo largo del período indicado Assalit recibió una remuneración total de 4.150 sueldos, en moneda melgaresa, la de mayor difusión en la isla. Dicha cantidad se desglosaba en 4.000 sueldos, en concepto de honorarios, y 150 sueldos en concepto de flete de la embarcación que lo trasladó a la isla. El mencionado lugarteniente no recibió su salario en uno o varios plazos, sino en función de los ingresos y remanentes de la bailía de Mallorca. Por esta razón fueron numerosos los pagos realizados hasta completar dicha cantidad. En el cuadro siguiente he establecido las formas de pago, ya que incluyen aspectos tan novedosos como la intermediación de las bancas privadas en el proceso.

El cuadro siguiente es elocuente tanto de la forma de funcionamiento de la administración real en isla, como de la remuneración asignada al lugarteniente, la más elevada entre los funcionarios reales, aunque sólo ligeramente por encima de la percibida por el baile. Por otra parte, a disposión del lugarteniente se encuentra ya una escribanía, servida por el notario Domingo Gil, y agentes ejecutivos como los troters y missatges?.

Pero durante este período y a lo largo de la mayor parte del siglo la figura del lugarteniente queda considerablemente oscurecida en comparación con la de los batlles de Mallorca. Serán estos últimos quienes vayan a Menorca a pendre postat y quienes presidan y den su consentimiento a los nuevos jurados elegidos, según se dispone en la carta municipal de 1249. Este carácter preponderante, dentro de la administración real, de la bailía provocará algunos casos de carreras meteóricas dentro de la administración real. Este fue el caso de Arnau Safont que de gestor del patrimonio de Nuño Sans en Ibiza, pasó a administrar la porción del conde del Rosellón en Mallorca, adquirida por el rey en 1242, y finalmente, en 1246, a ocupar el cargo de baile de Mallorca. Pero Safont no se limitó a una carrera administrativa ascendente, sino de que desde el primer momento se involucró en el mundo de los negocios. Es posible que ya en Ibiza adquiriera el arrendamiento las rentas de la mencionada porción, pero una vez

1 L. PÉREZ MARTÍNEZ, Corpus documental balear. Época de Jaime I, en «Fontes Rerum Balearium» I, 1977, doc. 83, pp. 94-95.

2 P. CATEURA BENNASSER, Las cuentas de la colonización feudal (Mallorca, 1231-1245), «En la España Medieval» 20, 1997, pp. 108-109. 


\begin{tabular}{|c|c|c|c|}
\hline Fecha del asiento & $\begin{array}{l}\text { Origen del mandamiento } \\
\text { de pago }\end{array}$ & $\begin{array}{l}\text { agente o Institución } \\
\text { pagadora }\end{array}$ & $\begin{array}{l}\text { agente que recibe el dinero } \\
\text { en nombre de Assalit }\end{array}$ \\
\hline- & bailía & banca de Guillem de Temines & A. d'Olives, 571 sueldos \\
\hline- & bailía & Bernat de Cardona & 200 sueldos \\
\hline- & bailía & Bernat de Cardona & G. Sasala, 400 sueldos \\
\hline l'endemà de Sent Vicens & bailía & R. Safont & 300 sueldos \\
\hline el mismo dia & bailía & - & Domingo Gill, 20 sueldos \\
\hline- & bailía & Comendador del Temple & 110 sueldos \\
\hline- & bailía & Mateu de na Guascunya & Domingo Gill, 140 sueldos \\
\hline- & ballía & el mismo & Miquel Periz, 60 sueldos \\
\hline dissapte ans de Nadal & bailía, en casa d'en Blasco & - & Domingo Gil, 179 sueldos \\
\hline- & bailía & J. de Juseu & Domingo Gil, 50 sueldos \\
\hline- & bailía & - & Domingo Gil, 440 sueldos \\
\hline 10 darrer dimartz de febrer & bailía & - & Domingo Gil, 160 sueldos \\
\hline to primer diliuns de mars & bailía & P. Setzera & Domingo Gil, 200 sueldos \\
\hline- & bailía & - & 50 sueldos \\
\hline- & bailía & P. Setzera & Domingo Gil, 20 sueldos \\
\hline divendres ans de Sent Gregori & bailía & P. Setzera & Domingo Gil, 40 sous \\
\hline- & bailía & Bernat de Cardona & G. Sasala, 60 sueldos \\
\hline 10 dijous migant mars & bailía & - & Domingo Gil, 70 sueldos \\
\hline $\begin{array}{l}\text { diluns ans de Sancta Maria } \\
\text { de mars }\end{array}$ & bailla & - & Domingo Gill, 30 sueldos \\
\hline- & bailía & - & Domingo Gil, 50 sueldos \\
\hline- & $\begin{array}{l}\text { summa major de so que } \\
\text { avem pagat an Assalit: } \\
\text { III millia, } C L \text { sous, los quals } \\
C L \text { sous foren pagats per to } \\
\text { nòlit. }\end{array}$ & - & - \\
\hline
\end{tabular}

en Mallorca su actividad fue febril en el mundo de los negocios. En 1244 arrendó al monarca las rentas y derechos de la antigua porción de Nuño Sans en Mallorca, distrito del que era lugarteniente real, además de reservarse para sí la castellanía de Santueri, ubicada en dicho territorio. También adquirió al monarca una gran alquería, tasada en 2.000 sueldos, que dejó pendiente de abonar. A través de intermediarios exportó todas las producciones arrendadas y entre 1246 y 1253 , cuando tuvo un control efectivo de todas las rentas reales, reorganizó el sistema de administración procediendo a la subasta de todos los derechos reales en lugar de seguir con el sistema tradicional de su gestión directa por la administración. El tributo de Menorca en lugar 
de ser distribuido en Mallorca y aquí vendido a diferentes intermediarios, donado a diferentes beneficiarios, invertido en las reservas reales o reenviado en parte a BarceIona fue directamente exportado, desde Menorca, a diferentes mercados exteriores. Por otra parte, Safont pasa a controlar el mercado de arrendamiento de rentas de otras porciones señoriales, como la de Bernat de Santa Eugènia.

Esta carrera, sin embargo, quedó truncada en 1253, cuando Jaime I le cesó como baile de Mallorca y ordenó el embargo de sus bienes por valor de 14.000 sueldos para cubrir deudas contraídas con el rey y con particulares. ${ }^{3} \mathrm{~A}$ raíz de este suceso, los lugartenientes pasan a denominarse procurator et tenens locum illustrissimi domini regis Aragonum in regno Maioricarum, lo que parece indicar un reforzamiento de las atribuciones de los lugartenientes en detrimento de los bailes ${ }^{4}$.

Tres años después, Jaume I tomó una decisión de gran calado. Se trataba de poner las bases de la sucesión del reino de Mallorca a favor de su hijo el infante Jaime. A principios de agosto de 1256 el rey comunicaba a los jurados y prohombres de la Universidad de Mallorca el desplazamiento de su hijo a la isla con la doble finalidad de jurar las franquicias del reino y a su vez ser aceptado como heredero del reino. El rey no se limitó a este acto protocolario, sino que para establecer una relación más firme entre su sucesor y el reino de Mallorca le confirió atribuciones, como la de gestionar el asentamiento de pobladores, y un patrimonio personal, la porción ibicenca heredada por el rey del infante Pedro de Portugal. Todos los elementos anteriores fueron reforzados con nuevas medidas, como la de conferirle, en 1262, idénticas atribuciones en los condados del Rosellón, Cerdanya y Conflent, concederle mayor discreccionalidad en la gestión del patrimonio real en la isla, realzando su posición inicial de procurador hasta convertirla prácticamente en una lugartenencia.

Esta dualidad —el rey decide, el infante gestiona - provoca, al menos durante cierto tiempo, distorsiones en la organización administrativa de la isla. El infante Jaume no pasó a residir permanentemente en la isla, sino que en la práctica estableció un sistema de visitas cada tres años aproximadamente. Por otra parte las funciones que inicialmente le fueron asignadas eran las propias del baile de Mallorca, por lo que el solapamiento de funciones resultaba evidente. En relación directa con lo anterior se encontraba el tema de la posición del mencionado infante respecto a los funcionarios reales establecidos en la isla - básicamente el lugarteniente, el veguer y el batlle-.

Dichas cuestiones no tardaron en clarificarse. A partir de 1259, sino antes, los lugartenientes y demás oficiales pasan a ostentar el cargo en nombre del infante. Así to hizo Berenguer de Tornamira al extender los documentos como tenens locum domini infantis Jacobi in Maioricis. En 1262, poco después de un nuevo testamento del rey en el que consolidaba los derechos sucesorios del infante Jaume sobre el reino de Ma-

3 ARM, ECR 342, fol. 235 r. El rey encargó su ejecución al portero Pere des Pont quien procedió a subastar y adjudicar tres alquerías de Arnau Safont.

4 Esta era la titulación utilizada por Berenguer de Tornamira, en 1253 (ARM, ECR 342, fol. 225 r.). 
llorca y los condados continentales, esto último procedió a relevarse de la procuración, delegando en el mencionado lugarteniente Pere de Tornamira ${ }^{5}$.

El absentismo del rey y del infante y la cortedad de recursos asignada inicialmente a este último determinan un desarrollo peculiar de la administración real durante los veinte años de infantazgo (1256-1276) de forma que vuelve a ser corriente que los cargos se entreguen a acreedores del infante Jaime. Con ello parece registrarse un retroceso en los esfuerzos realizados en el período anterior por profesionalizar la función pública.

La instrumentalización económica de los cargos de designación real determina la aparición de un léxico ambiguo y oscilante para referirse a los oficiales reales. En el mencionado período los lugartenientes se autotitulan como tenens locum, y especialmente como procurator et tenens locum y como baiulus et tenens locum ${ }^{6}$. Para completar la confusión el título de baiulus precede al de tenens locum y a menudo un mismo titular se presenta en unos documentos como baiulus y en otros como tenens locum? .

En 1264, el infante Jaume reconocía deudas por valor de 91.000 con diferentes particulares. Su principal acreedor —además de fiador del resto de los créditos recibidos por el infante - era Aries Ibáñez, un caballero de su séquito, por valor de 29.000 sueldos. En febrero del mencionado año, el infante firmaba carta de reconocimiento de deudas, estipulando la amortización de las mismas. Dado que Aries Ibáñez era el principal acreedor, además de fiador, el infante le transfiere todas las rentas y derechos que percibe en el archipiélago. Las estipulaciones concretas fueron las siguientes:

a) Aries Ibáñez, como principal acreedor, podría disponer de todas las rentas mencionadas hasta su completa satisfacción.

b) Durante este período, el infante se comprometía a no consignar ningún pago contras las mismas.

c) El mencionado acreedor podría nombrar los batlles que considere necesarios para recaudar dichas rentas y derechos.

d) Asimismo quedaba autorizado para nombrar un lugarteniente, tanto si estuviera presente como ausente del territorio. En el caso de que Aries lbáñez se constituyera a sí mismo en lugarteniente o si decidiera nombrar a otro en lugar possitis vel possit facere omnia que tenens locum nostrum ibidem facere possit et etiam consuevi $\beta^{\text {. }}$.

A partir de entonces se produce una reestructuración administrativa. Pere de Caldés, baile de Mallorca desde $1263^{9}$, pasa a convertirse también en lugarteniente, mateniéndose en el cargo hasta $1276^{10}$. La ocupación de los cargos de representación real por acreedores del infante determinó las consabidas distorsiones en el funcionamiento administrativo y político del reino.

5 ARM, ECR 345, fol. $69 \mathrm{~V}$.

6 ARM, ECR 345 , fol. $167 \mathrm{r}$.

7 ARM, ECR 347, fol. $95 \mathrm{v}$.

8 E. PASCUAL y E. de K. AGUILO, Noticias y documentos del siglo XIII, «BSAL" IV, p. 181. 
Algunas disposiciones tomadas por Jaume I a finales de su reinado ponen de manifiesto esta situación. Es cierto que su enmienda suponía una censura explícita de las actuaciones de su hijo, de ahí la levedad de las medidas adoptadas para corregir ciertas situaciones. Entre 1269 y 1273, figuran sin embargo algunas medidas reveladoras:

a) Contra los intentos de subordinación del municipio: En 1273, Jaume I ordenaba a los oficiales reales -especialmente al bat/le e el respeto a la carta municipal de 1249, absteniéndose de realizar negun empatxament en contrari ${ }^{11}$.

b) Contra los procedimientos judiciales dilatorios: El rey estableció, en sendos privilegios de 1269 y 1273, la duración de los procesos, los casos concretos en que podían dilatarse las sentencias y el plazo máximo para dictarlas, restableciendo lo dispuesto en la carta de franquicias de 1230 sobre las fianzas.

c) Moralización administrativa: La profesionalización de los cargos de representación real quedó circunscrita al veguer. En 1273, el rey ordenó que dicho cargo no pudiera ser objeto de compraventa o acceder a él por vía crediticia. Lugartenencia y bailía quedan fuera de la prescripción real posiblemente por estar todavía vigente el contrato de amortización de deudas del infante con Aries Ibáñez.

Los capítulos anteriores son elocuentes de las relaciones administración realmunicipio y del funcionamiento de la primera. En este ambiente cabe contextualizar, quizás, una revuelta suscitada en torno al pago de tasas portuarias. En efecto, en 1275 el guardián del puerto de Portopí, encargado del cobro del ancoratge y de tasas sobre entrada y salida de sarracenos, rendía cuentas de su administración. Además, en gesto desacostumbrado, el mencionado solicitó que se le absolviera de cualquiera tipo de responsabilidad económica desde el momento que tomó posesión de su cargo hasta la fecha indicada. La cautela tenía su razón de ser en que los documentos anuales, donde constaba dicha absolución, le habían sido destrozados quando furor populi Maioricarum $^{12}$.

\subsection{Los lugartenientes de los reyes de Mallorca}

En 1276, Jaime II tomaba posesión del reino de Mallorca. Comenzaba un nuevo proyecto político, la llamada Corona de Mallorca, integrada por territorios de diferente titularidad: un reino, el reino de Mallorca, dos condados pirenaicos -el Rosellón y la Cerdaña-, un señorío - sobre Montpellier- y dos vizcondados — los de Omeladés y de Carladés-. Dentro de esta entidad política destacaban dos ciudades, la Ciutat

9 ARM, ECR 643 , fol. $13 \mathrm{r}$. En agosto de este año procedía a adjudicar el derecho de pesca y caza en la Albufera de Mallorca por 810 sueldos a una sociedad.

10 En 1273 se intitulaba baiulus et tenes locum domini infantis Jacobi in Maioricis, procediendo a absolver a dos mercaderes genoveses del saqueo e incendio de una nave sarracena.

11 E. de K. AGUILO, Antigues franqueses y privilegis del regne, «BSAL» V, p. 410.

12 P. CATEURA BENNASSER, Sobre el «infant en Jacme» y Mallorca (1256-1276), en "Mayurqa» 20 (1984), p. 139. 
de Mallorques, capital del reino del mismo nombre, y Perpiñán, que hacía las veces de capital del Rosellón y de las demás pertenencias pirenaicas y donde los reyes de Mallorca situarán su corte de forma permanente.

El comienzo de una nueva época no supuso cambios administativos. En la jura de privilegios de Jaime II de Mallorca, celebrada en setiembre de 1276, figura entre los testigos Berenguer Arnau batle e tenent loch del senyor rei en Malorcha ${ }^{13}$. Sólo años después se opera un proceso de deslinde de funciones. En torno a 1280 la administración real aparece nuevamente dirigida por el lugarteniente y por el batlle. El primero con funciones militares y de orden público (organización defensiva de la isla, delitos de herejía, fugas de esclavos) y el segundo dirigiendo y coordinando la administración económica del patrimonio real ${ }^{14}$.

La ocupación de Mallorca por el infante Alfonso en 1285 provocó algunos cambios importantes. De carácter semántico, como el hecho de que los lugartenientes pasan a denominarse procurador y lugarteniente. Asbert de Mediona, nombrado por el rey de Aragón inmediatamente después de la ocupación se intitula militis, procuratoris et tenentis locum in regno Maioricarum pro dicto domino rege ${ }^{15}$. Otros con mayor calado, ya que dicho procurador-lugarteniente pasa a desplazar al batlle en el control del municipio. En una primera etapa, el mencionado designó directamente a los regidores municipales. Después, según estipuló la carta municipal de 1287, dichos regidores eran elegidos con el consentimiento, consejo y voluntad del mencionado. En suma, pues, los cuadros dirigentes del municipio son convertidos prácticamente en funcionarios reales.

A cambio de la pérdida teórica de la autonomía municipal, el municipio fue confiado a los medios burgueses insulares, que habían apoyado la ocupación de la isla. El precepto municipal, establecido en 1249, de un jurado militar fue ahora eliminado en beneficio de un sistema, más acorde con el status económico, como era el de manos: mano mayor, mano mediana y mano menor.

El carácter político asignado a los procuradores-lugartenientes fue completado con otras disposiciones que afectaban este oficio:

1) Administración de justicia: Se establece la presencia obligatoria de los prohombres en los juicios y sentencias (1286) y su obligatoria inhibición de las competencias asignadas al batlle y veguer (1288).

2) Organización judicial del archipiélago: se realza la condición del procurador-lugarteniente de Mallorca al establecer la subordinación de sus homónimos de Menorca e Ibiza, poniéndose bajo su jurisdicción los recursos presentados a las sentencias dictadas por los tribunales de las islas menores $(1291)^{16}$. Dicha subordinación fue

13 E. de K. AGUILO, Franqueses y privilegis del regne, en el «BSAL» VII (1897-1898), pp. 3-4.

14 En 1284 ocupaba la lugartenencia Pons Saguàrdia, titular de la baronía de Canet, y la bailía A. Burgués, natural de la isla.

15 E. de K. AGUILO, Actes d'elecció de síndichs de la ciutat i de les parròquies foranes (1285), en el «BSAL» IX (1901-1902), p. 119.

16 J.M ${ }^{a}$ QUADRADO, Privilegios y franquicias de Mallorca, Palma de Mallorca, 1896, pp. 68-70. 
modificada por una ordenanza real de 1294. A petición del batlle general de Menorca y de Bernat Saguàrdia, representante de la Universidad, Jaime II de Aragón estableció que los oficiales reales de Menorca dependieran directamente del rey.

El tratado de Anagni, de 1295, y su complementario de Argilers, de 1298, determinaron la retrocesión del reino de Mallorca, en las mismas condiciones de infeudación de 1279, a Jaime II de Mallorca. La reintegración del archipiélago constituía un éxito político de Jaime II, aunque con las limitaciones apuntadas. De ahí el diseño de una política, de tono autoritario, destinada a la generación de recursos ${ }^{17}$. Esta priroridad establecida condiciona la reforma de la administración real en el archipiélago. De la misma me interesa destacar lo que atañe a la lugartenencia. Una de las primeras medidas al tomar posesión del reino, en 1298, fue el nombramiento de una lugarteniente general. Vale la pena detenerse en la carta de nombramiento porque establece un nuevo marco de la administración real:

1) El cargo recayó en Pere de Fenollet, el principal representante de la nobleza rosellonesa. Los Fenollet habían sido titulares del vizcondado del mismo nombre, que habían perdido a raíz de la guerra de los albigenses. Pere de Fenollet era en aquellos momentos señor de llla i de Joc, que serán elevados a vizcondado en $1314^{18}$. Por consiguiente, Jaime II de Mallorca otorga el máximo rango al nuevo nombramiento.

2) Se trataba de una lugartenencia general dotada de máximos poderes o como se indica textualmente en el documento vice et loco nostro. Esto implicaba la prerrogativa de nombramiento y deposición de todos los oficiales reales del reino et generaliter omnia alia faciendi et exercendi que nos facere possemus ${ }^{19}$.

Esta lugartenencia reforzada, una especie de virreinato, tenía su razón de ser en los planes políticos y administrativos diseñados por la Corona en las islas Baleares entre los que se encontraba la subordinación del municipio, una vasta política de colonización interior y el establecimiento de tributos.

A través de la documentación conservada podemos establecer una relación bastante completa de los lugartenientes de las islas durante el período de la dinastía privativa ${ }^{\text {?o: }}$

17 En 1300 el rey Jaime Il concedía un indulto a todos los habitantes de las islas, pero a cambio estableció una sisa real a modo de penalización.

18 Varii: Lleis Palatines, Palma de Mallorca, Conselleria de Cultura, Educació i Esports, Govern Balear, Vol. 1, 1991, p. 65.

$19 \mathrm{~J}$ VICH y J. MUNTANER, Documenta regni Maioricarum (miscelánea), Palma de Mallorca, 1945, doc. $\mathrm{n}^{\circ} 45$, p. 57 .

20 Datos extraidos de J. VICH y J. MUNTANER, Documenta regni Maioricarum.., pp. 9-193; E. de K. AGUILO, Lletres reials, en el "BSAL»XX,pp. 260,339, 359; XXI, p. 41; XXII, pp. 43, 55, 68, 155, $164,213,236,302,328,355,385 ;$ XXIII, pp. 29 y 40; del mismo autor Rúbrica de Lletres Comunes, en el «BSAL», XXI, pp. 66, 210, 269; XXII, pp. 7 y 22; R. ROSSELLO, Aportació a la història medieval de Menorca (segle XIV), Menorca, Consell Insular, 1985; J. SASTRE, Economía y sociedad del reino de Mallorca (primer tercio del siglo XIV), Paima, 1986, pp. 42-43; ARM, AH-Lletres reials, vols. 3-8. 


\begin{tabular}{|c|c|c|}
\hline Mallorca & Menorca & Ibiza-Formentera \\
\hline $\begin{array}{l}\text { 1301-1302: A) Berenguer de Calders, } \\
\text { cavaler, loctinent en lo regne de Malorques } \\
\text { B) Miró de Palau (portantveus) }\end{array}$ & $\begin{array}{l}\text { 1302: Pere Bernat de Puigdorfila, } \\
\text { batlle de Menorca }\end{array}$ & $\begin{array}{l}\text { 1303: Bernat Safortesa, baiulo et } \\
\text { tenenti locum nostrum in insula } \\
\text { Evisse et Formentarie }\end{array}$ \\
\hline $\begin{array}{l}\text { 1302-1306: Dalmau Sagarriga, militi, } \\
\text { tenenti locum nostrum in regno } \\
\text { Maioricarum }\end{array}$ & $\begin{array}{l}\text { 1303: Pere de Libià, batlle de } \\
\text { Menorca }\end{array}$ & - \\
\hline $\begin{array}{l}\text { 1306-1310: Pere de Belicastell, milite } \\
\text { at tenente locum }\end{array}$ & - & - \\
\hline $\begin{array}{l}\text { 1311-1316: A) Berenguer de Sant Joan, } \\
\text { milite, tenente locum nostrum in regno } \\
\text { Maioricarum (nuevos mandatos en } \\
1318 \text { y } 1321 \\
\text { B) Gil Garcés (gerenti vices) }\end{array}$ & $\begin{array}{l}\text { 1311-1313: Gil Garcés } \\
\text { 1314-1315: Berenguer Desbac, donzell } \\
\text { 1315: Berenguer de Luc, locumtenens } \\
\text { in insula Minorice }\end{array}$ & $\begin{array}{l}\text { 1311: R. de Parayols } \\
\text { 1313: Francesc Duran }\end{array}$ \\
\hline $\begin{array}{l}\text { 1320-1321: Dalmau de Banyuls, militis } \\
\text { tenenti locum nostrum }\end{array}$ & 1320-1323: Jaume de Mora (Muredine) & - \\
\hline $\begin{array}{l}\text { 1323-1325: Bernat de Tornamira, } \\
\text { cavaler, loctenent }\end{array}$ & $\begin{array}{l}\text { 1324: A) Bernat de Vallauria, loctinent } \\
\text { B) Ferrer Malferit, portant veus }\end{array}$ & 1323: Berenguer Desbac, donzell \\
\hline 1325-1326: Guerau Adarró & 1325-1326: Bernat Umbert & - \\
\hline $\begin{array}{l}\text { 1326-1330: Arnau de Cardellac, } \\
\text { locumtenenti Maioricarum B) Berenguer } \\
\text { Santa Cilla, cavaler, portantveus } \\
\text { B) Huc de Paretstortes, portantveus } \\
\text { C) Berenguer Desbac, portantveus }\end{array}$ & 1326: Guillem de Sant Joan, loctinent & - \\
\hline $\begin{array}{l}\text { 1330-1336: Pere de Bellcastell, militi, } \\
\text { domino de Villalonge, locum nostrum } \\
\text { tenenti }\end{array}$ & $\begin{array}{l}\text { 1329-1330: A) Dalmau de Totzó, } \\
\text { loctinent B) Ferrer Malferit, portantveus } \\
\text { 1330-1336: A) Pauquet de Bellcastell, } \\
\text { loctinent B) Ramon de Sant Martí } \\
\text { 1336: Pere Ramon de Codalet, } \\
\text { cavaler e loctinent }\end{array}$ & 1332-1335: Ramon Muntaner \\
\hline $\begin{array}{l}\text { 1336-1343: A) Roger de Rovenach, } \\
\text { miles, locumtenenti B) Ramon de } \\
\text { Capcir, assessor e loch de lochtinent } \\
\text { (1337) C) Huc de Totzó, cavaller e } \\
\text { portantveus (1338-1340). }\end{array}$ & $\begin{array}{l}\text { 1337: Pauquet de Bellcastell, loctinent } \\
\text { 1338-1340: Berenguer Desbac, } \\
\text { donzell, loctinent } \\
\text { 1340-1341: Pere Onis, donzell, loctinent }\end{array}$ & 1337: Dalmau de Totzó \\
\hline
\end{tabular}


El cuadro anterior presenta cuestiones de interés. La lugartenencia de Mallorca queda reservada casi en exclusiva para caballeros del Rosellón. Los caballeros mallorquines cubren interinidades, en calidad de portantveus, y a partir del rey Sancho la lugartenencia de Menorca e Ibiza. Pero en estos últimos casos suelen destinarse a donzells, que realizan un aprendizaje administrativo y de mando en las islas menores. Apararecen también las primeras sagas familiares, como los Sant Joan y los Totzó, en la que padres e hijos ocupan cargos en Mallorca y Menorca.

No todos los lugartenientes de este período fueron designados por el rey. En las circunstancias extraordinarias del fallecimiento del rey Sancho sin herederos directos, el reino de Mallorca protagoniza un movimiento de tipo pactista, reclamando su participación en el consejo real, en los oficios de la Casa Real e incluso el nombramiento de los oficiales reales de las islas. Todas estas reclamaciones fueron aceptadas por el infante Felipe, tutor de Jaime III, en 1325. Como resultado, los Jurados y la Universidad de Mallorca procedieron a designar a los lugartenientes de Mallorca, Menorca e Ibiza, batlles y veguers. En el caso de Mallorca, los jurados designaron al caballero Guerau Adarró, y en el de Menorca al ciudadano Bernat Umbert.

Los lugartenientes de Mallorca eran remunerados con cargo a la Procuración Real con 3.000 sueldos anuales ${ }^{21}$. Sin embargo, no fue infrecuente que los reyes de Mallorca remuneraran servicios, considerados extraordinarios, de los lugartenientes insulares. Este fue el caso de Arnau de Cardellach, cuyo mandato coincide con la restauración del poder monárquico en las islas tras los acontecimientos de 1325. Jaime III decidió premiar sus trabajos con la concesión, en feudo, de la baronía de Buyola. Para ello, le asignó una renta anual de 5.000 sueldos procedentes de rentas agrarias, derechos de traspaso (laudemios) y de justicia ${ }^{22}$. La potenciación de la pequeña nobleza rosellonesa había sido y era una directriz básica de la dinastía de Mallorca. Caballeros convertidos en barones incluso burgueses convertidos en caballeros. Pero la novedad era la incorporación de las islas a este proceso, creando en su territorio espacios dominicales a favor de caballeros del Rosellón.

La estructura política, creada por los reyes de Maliorca, determina que el reino de Mallorca sea gobernado desde Perpiñán. Esto significa que en tanto gentes del Rosellón son designados para cubrir las lugartenencias insulares, en ningún caso caballeros de las islas resultan nombrados para ocupar cargos similares en el Rosellón o la Cerdaña. Se trata, pues, de una estructura funcional de centro y periferia, capital y provincia.

El reformismo autoritario inspirado por Jaime II de Mallorca y sus sucesores tuvo su réplica en el reforzamiento de funciones de los lugartenientes. El protagonismo ejercido por los batlles en el siglo XIII cede ahora el lugar a los lugartenientes, en temas de orden político, judicial y administrativo, y a los procuradores reales, en cues-

21 E. de K. AGUILO, Lletres reials XXII (1928-1929), p. 44. El rey, en carta a los procuradores reales de Mallorca, les comunicaba el nombramiento de Guillem de Sant Joan como lugarteniente y la asignación del precitado sueldo.

22 J. VICH y J. MUNTANER, Documenta., pp. 144-147, doc. no 130. 
tiones económicas. No por casualidad se abren en este período nuevas series documentales en relación con la actividad de los lugartenientes como Suplicacions, Lletres reials o Lletres Comunes.

En el plano jurídico, los libros de privilegios y ordenanzas reales se hacen eco de la regulación de competencias de los lugartenientes:

- Destacan en primer lugar las dirigidas al control de las actividades judiciales de los señoríos (baronías de Bearn, del conde de Ampuries, y de los obispos de BarceIona y Mallorca). En unas instrucciones, elaboradas por Jaime II hacia 1301, el rey encomendaba al lugarteniente la tutela del ejercicio de la justicia en dichos señoríos, reservando a la curia del lugarteniente las segundas apelaciones a las setencias dictadas por los jueces señoriales, y excluyendo de la jurisdicción de éstos los delitos cometidos por extranjeros o nuevos residentes.

- En cuanto al procedimiento judicial, los lugartenientes o mejor su curia deben juzgar y promulgar las sentencias con una comisión de prohombres, fijada en ocho, de los cuales dos, si era posible, debían ser jurisperitos.

-_ En 1316, el rey Sancho de Mallorca regulaba las competencias de los Jurados en orden a la publicación de constitutiones, ordinationes seu capitula elaborados para utilidad pública, estableciendo su revisión previa y obligatoria por el lugarteniente. Asimismo, los estatutos y ordenanzas elaboradas por los lugartenientes debian ser comunicados previamente a los Jurados por si lesionaran los privilegios el reino ${ }^{23}$.

- Finalmente, los lugartenientes tenían jurisdicción exclusiva sobre los miembros del estamento militar de las islas, tanto en el terreno judicial como en el militar —con la convocatoria de caballos armados-y tributario ${ }^{24}$.

Como vemos, los lugartenientes actúan como jueces ordinarios y jueces de apelación, debiendo adaptar sus sentencias al cuerpo jurídico del reino, integrado por privilegios y franquicias, cuya defensa corre a cargo de los prohombres. También, a partir de 1316 , se les reconocían facultades reglamentarias.

\subsection{Gobernadores y lugartenientes generales}

La incorporación del reino de Mallorca a la Corona de Aragón, en 1343, provoca algunos cambios importantes:

- Cambios semánticos, pero no desdeñables, como la nueva titulación de gobernadores que se adjudica a los máximos representantes de la Corona en las islas. La palabra lugarteniente quedó a partir de entonces reservada para estratos superiores - lugartenencias generales adjudicadas a familiares del rey-o inferiores —interinos de los gobernadores-. La nueva denominación trata de adaptar los territorios recién

23 ARM, Códice Abelló, fol. $91 \mathrm{r}$.

24 En 1302, el lugarteniente de Mallorca apremiaba a los caballeros de Menorca a contribuir en las obras de construcción de iglesias. El mismo año, en carta la batlle real de Ibiza, el lugarteniente de Mallorca mediaba a favor de un vecino de lbiza, acreedor del señor de Brish (E. de K. AGUILO, Lletres reals.., XX, pp. 265 y 341, docs. no 73 y 107. 


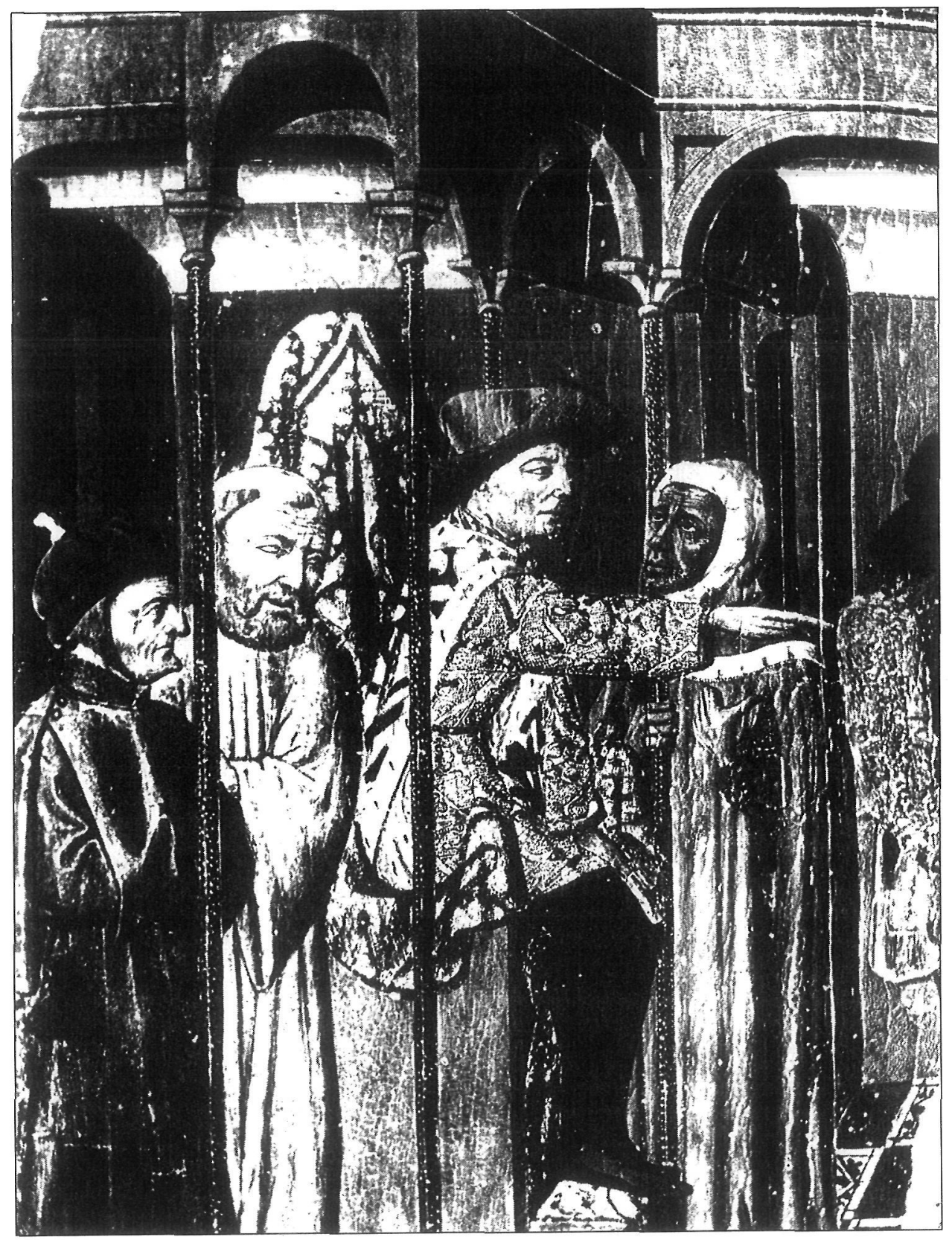

Foto1. Juez administrando justicia, en presencia de los prohombres (Palma de Mallorca, Maestro de las predelas, siglo XV). 
incorporados a un modelo homogéneo establecido en los demás territorios de la Corona, de ahí los gobernadores del Rosellón y de Mallorca.

- Resulta curioso que una de las primeras ordenanzas dictadas por Pedro IV, después de la reincorporación de 1343, se refiera al origen de los gobernadores. En efecto, el rey establecía que deberían ser de procedencia catalana, excluyendo expresamente a los procedentes del Rosellón o Aragón. La catalanización de dicho cargo, por lo demás ya establecida por su predecesor Jaime II de Aragón, no deja de ser sorprendente, por las limitaciones que se autoimponía la Corona en este terreno y porque el Rosellón era considerada tierra catalana, sin discusión. Además, el mismo rey incorporó a su administración a numerosos roselloneses a partir de 1345. Si el rey pensaba que un gobernador procedente del Rosellón podía despertar, en Mallorca, nostalgias de tiempos periclitados — cuando ambos territorios estaban unidos- estaba mal informado. Basta remitirse a lo que he señalado en páginas anteriores sobre las quejas de los insulares sobre el desigual peso político de ambos territorios.

- Finalmente, cabe señalar, como característica general, que los gobernadores asumen a partir de mediados del siglo XIV la función de inrtermediarios entre el municipio y la Corona en la negociación de subsidios. La tarea no resultó difícil. El reino había sido ocupado en 1343 sin apenas violencias, pero no debemos olvidar que el rey quiso rememorar, aunque fuera símbolicamente, la conquista de Mallorca por su predecesor Jaime I al desembarcar en el mismo lugar de la costa que aquél. También cabe indicar que el rey vino a Mallorca con un nutrido ejército, entre los que el mismo monarca destaca a los almogávares. Estamos por consiguiente ante una verdadera escenografía de guerra, aunque ésta, en sus gestos rituales, no llegara a cristalizar en acciones militares de calado. Estos hechos son los que explican la posición de la Corona en el nuevo reino incorporado. Posición de fuerza que le permite, desde un buen comienzo, una política de subordinación del municipio.

Las circunstancias anteriores convierten al gobernador de Mallorca en una pieza clave de la política real, sobre la que el monarca cimenta su estrategia de autoridad. En esta dirección apuntan tanto su regulación orgánica como las competencias que asumen durante este período. Son gobernadores generales, en tanto en cuanto su titulación incluye la ciudad y reino de Mallorca e islas adyacentes y tienen encomendado tot lo regiment del dit regne ${ }^{25}$, aunque Menorca e Ibiza fueran regidas por sus respectivos gobernadores o portantveus. En 1346, al revisar el monarca los delitos calificados de lesa majestad, incluyó en ellos el de homicidio o lesiones al gobernador.

En su calidad de máximo representante real era consecuentemente el funcionario mejor remunerado. Mientras que el último lugarteniente de Mallorca, Roger de Rovenach, ingresaba anualmente 7.640 sueldos, el primer gobernador nombrado por Pedro IV, Arnau d'Erill, pasó a cobrar 10.000 sueldos. En 1348, el gobernador Gilabert de Centelles pasó a cobrar 14.000 sueldos. A partir de entonces el sueldo de los

25 ARM, Códice Sant pere, fol. 94 v. 
gobernadores quedó congelado, aunque el rey procedía a premiar sus servicios con remuneraciones extraordinarias ${ }^{26}$.

Durante la época de Pedro el Ceremonioso los gobernadores no dejaron de consolidar e incluso extender sus competencias, incrementando una ya holgada documentación que sobre el mismo cargo había recaído desde épocas anteriores. En la segunda mitad del siglo XIV los gobernadores del reino de Mallorca adquieren el perfil, prácticamente definitivo, de sus competencias:

a) Competencias normativas: Ya establecidas en 1316, y que los gobernadores no dejaron de utilizar. Así Arnau d'Erill, en 1344, con su reglamentación o Stils, y otra similares elaboradas por el gobernador Francesc Sagarriga, en 1378, y el virrey Huc d’Anglesola, en 1398. Las facultades reglamentarias de los gobernadores no sólo afectaron al mundo judicial sino también al municipal y gremial.

b) Competencias judiciales, atribuidas al gobernador o mejor a su curia. En este ámbito el gobernador puede actuar como juez ordinario, como juez de apelación y como juez delegado. En el primer caso tiene atribuidos los delitos de falsificación de moneda, de lesa majestad, de herejía, los delitos cometidos por caballeros y por oficiales reales y los que se cometieran en el recinto de la Almudaina, sede de los gobernadores. Era juez de apelación de las sentencias dictadas por los batlles de las villas y de los gobernadores de Menorca e Ibiza. También juzgaban las segundas apelaciones de los batlles de los señoríos y las primeras de las sentencias interlocutorias. Finalmente le correspondía designar los jueces delegados para juzgar las apelaciones de las sentencias del batlle y veguer de la ciudad y él mismo podía actuar como juez delegado, en los casos que le asignara el rey.

Por mandato de la Carta de Franqueses de 1230, el gobernador debía juzgar con un consejo de prohombres, establecido en ocho por Jaime II en 1299. Esta garantía constitucional, en la aplicación del derecho, fue abolida por Pedro el Ceremonioso. El gobernador Olfo de Prócida (1365-1375) dejó de convocar el consejo de prohombres, juzgando exclusivamente con el asesor y con algún jurisperito a su discrección. Pese a la oposición de los Jurados, en 1367, el rey dio carta de naturaleza a la actuación del mencionado gobernador. A partir de entonces, la norma de la presencia de prohombres en las sentencias era sólo de aplicación a las curias de los veguers y batlle.

c) Las competencias militares eran compartidas con la Universidad. El gobernador estaba al mando de las tradicionales tropas feudales -integradas por los titulares de feudos reales o caballerías-. Los jurados designaban a los vigías (talauyes $i$ escoltes) y corrían de su cuenta las obras defensivas necesarias. Gobernador y jurados compartían el mando de la flotilla de defensa de las islas —llamada del pariatge-, cuya plantilla era de cuatro galeras ${ }^{27}$.

26 ARM, RP-3388, fols. 10 r.-10 v. y 15 r.

27 J. VICH y J. MUNTANER, Documenta.., pp. 121-123, doc. $n^{\circ} 110$. En el contrato de pariatge se establecía que el rey nombraría un almirante y lo propio harían los jurados. 
d) Un aspecto no desdeñable de las funciones de los gobernadores era la protección de los judíos. Desde la fundación del reino de Mallorca, los judíos habían quedado bajo protección real. Pero su aceptación como ciudadanos de pleno derecho tardó en materializarse. Solamente a partir de 1307 se les reconoce, a título particular, comprar bienes raíces (tanto el dominio útil como el directo) y sólo en 1325 se les otorga su condición de ciudadanos de Mallorca ${ }^{28}$. Pero IV de Aragón tuvo una actitud más activa en defensa de la comunidad judía. En 1347 y nuevamente en 1356 estableció que los oficiales reales debían jurar, anualmente al tomar posesión de su cargo, los privilegios y libertades de los judíos. La norma se cumplió puntualmente debido al requerimiento que realizaban anualmente los secretarios de la aljama ${ }^{29}$. Dicha protección tuvo oportunidad de practicarse en 1391, en el curso del asalto al call de la ciudad, cuando el gobernador acogió a los judíos sobrevivientes en la Almudaina o palacio del gobernador.

e) Las cuestiones de contrafuero. Desde la toma de posesión por Pedro el Ceremonioso, en 1343, se habían producido numerosas transgresiones de los privilegios y franquicias del reino. Como botón de muestra estaba el tema de las confiscaciones de bienes a los condenados a muerte - según los privilegios vigentes estos bienes debían pasar íntegramente a los herederos del condenado- ${ }^{30}$ y los recursos presentados a tribunales de fuera del archipiélago. La acumulación de casos similares inspiró un clamor, rápidamente cortocircuitado por el rey al establecer por una parte, en 1369, que cualquier carta real, lesiva para los privilegios, fuera considerada nula, y que fuera el gobernador quien dictaminara sobre el particular.

El asalto al call y otros incidentes, como el asedio del castillo de Bellver, donde se habían refugiado prominentes ciudadanos y caballeros, aconsejaron medidas de fuerza, de ahí el nombramiento de Huc d'Anglesola como viçrey en lo regne de Mallorca. El nuevo virrey atacó la problemática de la época, con una pragmática sancionada por el rey, desde tres frentes: el financiero, con una política de saneamiento, el político, con una reforma del régimen electoral, y el judicial. Con la finalidad de aliviar las tensiones internas, Anglesola organizó dos expediciones contra núcleos piráticos del Norte de África.

28 En aquella fecha, el infante Felipe, tutor de Jaime III, les concedía quod possint et valeant libere uti et gaudere omnibus franquesils, consuetudinibus et alis immunitatibus quibus utuntur et gaudent cives civitatis et regni Maioricarum. Sin embargo, poco después matiza dicho otorgamiento señalando prout, tamen, dicti judei usi sunt hactenus de eisdem. Es decir, les otorga la ciudadanía pero sólo tal como la disfrutaban hasta el momento.

29 En 1389, a solicitud de los mencionados secretarios, el gobernador ordenó jurar dichos privilegios a los siguientes oficiales en el acto de toma de posesión de sus cargos: batlle de la ciudad y su asesor, veguer de la ciudad y asesor, y veguer foráneo y asesor (ARM, AH- EO 7, fol. 6 r.).

30 En 1346, Pedro el Ceremonioso restableció la franquicia de libertad de testar a los condenados a muerte. 
En su calidad de mandatario con plenos poderes, Anglesola nombró y depuso funcionarios y asesores de los mismos ${ }^{31}$ y firmaba las convocatorias al Consell General, máximo organismo supramunicpal de Mallorca. La política de aprovisionamiento de granos, una de las que comportaba mayores gastos a la Universidad, fue puesta bajo supervisión del virrey.

Las medidas adoptadas por Anglesola tuvieron el efecto de atraerse a los sectores populares - campesinos y menestrales-que hicieron suyo el programa de reforma económica y electoral. Otra cuestión eran los sectores dirigentes de la isla que consideraban a las mismas lesivas para los privilegios y franquicias del reino y constrictoras de la autonomía municipal. Por ello, a partir de entonces se organizan corrientes de opinión y liderazgos que hacen suya una de las opciones. La opción aristocrática, que defiende la autonomía del municipio, defiende la carta fundacional del municipio, la de 1249, donde se consagra el sistema de cooptación en la renovación de los jurados y consell. La opción popular que hace suya la pragmática de Anglesola, donde se consagra la suerte como elemento de acceso a los cargos municipales, donde salvo los cargos de mostassaf y ejecutor los demás estaban abiertos a todos los estamentos, se incompatibiliza la ocupación simultánea de cargos reales y municipales, y donde todos los individuos capacitados debían ser insaculados y podían resultar elegidos.

Los sistemas electorales de Pragmática (a suerte) y de Franquesa (cooptación) estarán vigentes, de forma alternativa, a lo largo de la primera mitad del siglo XV, como símbolo del equilibrio de fuerzas entre los grupos mencionados. El problema era que no sólo el sistema de bandos afectaba al funcionamiento del municipio, sino también a la misma estructura de la administración real. Esto significaba que todos los cargos, incluida la gobernación, entraban dentro del horizonte, de la lucha por el poder.

Gobernar el reino de Mallorca en estas condiciones no era tarea fácil. De ahí que la monarquía, especialmente en la época de Alfonso el Magnánimo, diseñe una política de convivencia con los grupos de presión, preservando en lo fundamental los derechos reales y obteniendo de las partes una financiación regular para sus empresas. Una política posibilista como la que he señalado determinó un funcionamiento peculiar de la administración real hasta el punto de conferirla, de hecho aunque a precario, a gentes de las islas.

Dentro de este contexto fueran escasas, aunque significativas, las normas que regían la constitución orgánica de la gobernación y sus competencias. Una de las primeras normativas que cayeron fue la del origen de los gobernadores. Pedro IV, en una disposición ya comentada, había excluido expresamente a los roselloneses y aragoneses de la gobernación de Mallorca. Es suficientemente conocida la actitud de los procuradores catalanes, en el Compromiso de Caspe, respecto al candidato Trastámara. Por esta razón, Fernando I, al renovar la gobernación de Mallorca en 1415, se decidió por un valenciano, Olfo de Prócida. Evidentemente el nombramiento tenía el sello de

31 En abril de 1398 designaba a Antoni Squella como batlle de Mahón y en las mismas fechas nombraba a los asesores de los veguers y del batlle de la ciudad de Mallorca (ACA, Ca 2356, fols. 66 r. y 69 r.). 
la sutilidad. En el mencionado documento de Pedro IV no se aludía a los valencianos, por considerarlos, al menos por omisión, como catalanes. Fernando I se acogió a este supuesto, por omisión, para evitar el nombramiento de un candidato del Principado. Después, Alfonso el Magnánimo actuó abiertamente en este tema ya que en 1425 designó a Berenguer d'Olms, rosellonés, como gobernador. En el mismo documento de nombramiento, el rey declaraba abolida la precitada normativa de Pedro IV.

Martín el Humano, que había inspirado la política de redrés, ejecutada por Huc d'Anglesola, fue también el creador de un organismo peculiar. Se trata del Consell de Franquesa. La política desarrollada por el mencionado virrey había provocado numerosas infracciones al cuerpo de privilegios y franquicias del reino. La cuestión no era una novedad -la época de Pedro IV dio sobradas pruebas de lo mismo- pero posiblemente las actuaciones de Anglesola eran, a juicio de un sector de la opinión, la gota que colmaba el vaso. Por ello, los jurados promovieron la constitución de un organismo que velara por la vigencia e integridad de los privilegios y franquicias. Martín el Humano sorprendentemente no puso obstáculos a su creación. En 1404 instituía el aludido Consell de Franquesa. Ahora bien, el rey estableció unos estatutos y composición que frustraban ab initio su funcionamiento. Dicho consejo sólo podía ser convocado por el gobernador y estaría integrado por dicho cargo, los oficiales reales y sus asesores y dos jurisperitos nombrados por el monarca. El resultado de dicha propuesta fue, como puede preverse, condenar al Consell de Franquesa a la inoperancia. El único compromiso adquirido por la Corona en esta tema fue su declaración, establecida en 1427 , de no enviar virreyes o reformadores a Mallorca ${ }^{32}$.

Las competencias de los gobernadores del reino de Mallorca fueron recogidas, en un sumario, por orden del gobernador Roger de Moncada, en los primeros años del siglo $\mathrm{XV}^{33}$. Las mismas reflejaban, en exclusiva, el carácter central del cargo en el terreno judicial, como juez ordinario, como juez de apelación y como garante de la administración de justicia encomendada a batlles y veguers. Pero como tuve oportunidad de explicar, la gobernación de Mallorca tenía competencias que se extendían al terreno político y militar $y$, por supuesto era el intermediario entre la monarquía y el municipio a los efectos de negociar los subsidios.

Sin embargo, desde finales del siglo XIV el procurador real adquiere un rango no sólo económico sino también político convirtiéndose en un par del gobernador. Dicho cargo era confiado de forma invariable a insulares, generalmente a notarios. No era un cargo a precario, como el de gobernador, sino que solían ocuparlo por largos períodos, incluso vitaliciamente. Pero lo fundamental del procurador real era su conocimiento del medio sociológico y su habilidad para resolver los frecuentes problemas financieros de la Corona. Por todas estas razones se convierte en una figura funda-

32 Alfonso el Magnánimo aceptó este compromiso, ya establecido por sus predecesores Juan I y Martín el Humano respecto al envío de comisarios, añadiendo el de virreyes, cuyos poderes reforzados eran fuente principal de conflictos con los privilegios y franquicias del reino (ARM, Códice Sant Pere, fol. 146 v.). 
mental, dentro del esquema de la administración real, hasta el punto de ocupar las lugartenencias de gobernación o designar interinos de este cargo.

Durante la primera mitad del siglo XV el procurador real incrementó sus competenecias, al convertirse en juez, junto al gobernador, en los pleitos que afectaban a los derechos reales ${ }^{34}$ y tener el control de las escribanías ${ }^{35}$, lo cual significaba que era el personaje mejor informado del reino. Finalmente, en 1446, Alfonso el Magnánimo decidió eximir al procurador real, a su familia y a los titulares de su escribanía, convertidos en oficiales reales, de la jurisdicción del gobernador. Esto significaba que el Procurador Real sólo podría ser juzgado por el rey y que los escribanos estarían bajo la jurisdicción exclusiva del procurador ${ }^{36}$. De hecho se había instalado en Mallorca una especie de diarquía administrativa, aunque bajo el control de los procuradores reales ya que a menudo controlaban, aún a precario, la lugartenencia de gobernación.

Tras el telón de las competencias y jurisdicciones otorgadas a los gobernadores y procuradores reales se encontraba una realidad sociológica compleja. Por una lado, los intereses de los bandos - fuertemente personalizados en prominentes personajes- por subordinar el municipio y la administración real. Por otro lado, la monarquía interesada en mantener los resortes del poder y el drenaje económico. Ello suponía una estrategia política de equilibrio entre las partes y de asignación de cuotas de poder, jugar con las contradicciones existentes sin quemarse. La adscripción a estas líneas políticas dio una gran plasticidad al funcionamiento administrativo del reino de Mallorca.

Es cierto que el cargo de gobernador recaía siempre en personajes de fuera de la isla, pero con Alfonso el Magnánimo el cargo se adapta a las directrices políticas apuntadas. En 1415 el mencionado Olfo de Prócida fue designado gobernador de Mallorca. Pelayo Unís, miembro destacado de una facción, se opuso al nombramiento en base a que el designado era valenciano. El rey mantuvo su nombramiento, aunque colocando a Pelayo Unís como lugarteniente. En 1425, Alfonso el Magnánimo designó como gobernador a Berenguer d'Olms y lo mantuvo en el cargo nada menos que durante 26 años. A partir de entonces el esquema de funcionamiento de la gobernación y de las lugartenencias fue de una gran dinamismo y adaptabilidad.

En 1425, tras el fallecimiento de Olfo de Prócida, el procurador real, Lázaro de Loscos, caballero, designa a Ramón Safortesa como lugateniente de gobernador.

Al año siguiente, Lázaro de Loscos, pasa a ocupar la lugartenencia interina, de la cual es desplazado el mismo año por Pelayo Unís.

33 ARM, Códice Jurisdiccions e Stils, fols. $104 \mathrm{~V}-110 \mathrm{~V}$.

34 ARM, Códice Jurisdiccions e Stils, fol. $26 \mathrm{r}$.

35 En 1425 el rey establecía la validez de las provisiones de escribanías realizadas por el Procurador, anulando las expedidas por la Corte salvo que en ellas se hiciera mención expresa de una arrendamiento previo hecho por el Procurador. (ARM, R.P. 41, fol. 141 v.).

36 ARM, R.p. 42 , fol. 170 r. 
En 1430 el gobernador titular Berenguer d'Olms toma posesión del cargo, después de cinco años de ser nombrado. Al año siguiente se ausenta, dejando como lugarteniente a Lázaro de Loscos.

En 1432 actúa como lugarteniente Juan Desfar. Tres años después, Berenguer d'Olms retoma el mando por poco tiempo, ya que el mismo año 1435 designa como lugarteniente a Bernat de Lupià, rosellonés, aunque quien ejerce la lugartenencia es Lázaro de Loscos. La reina María ordena a Loscos, en 1437, que resigne el cargo en Lupià. El mismo año, Bernat de Lupià deja como regente de lugarteniente a su hermano Miquel de Lupià, doncel.

En 1440 Berenguer d'Olms reasume el cargo de gobernador, pero dos años después abandona la isla dejando como lugarteniente al Lázaro de Loscos, procurador real.

En 1444, el caballero Huc de Sant Joan es nombrado lugarteniente por tiempo de tres años, sin embargo al año siguiente la reina María nombra como tal a Ramón Canet, quien fallece antes de ocupar el cargo. A continuación la reina nombra a Bernat Çalba quien, a poco de tomar posesión del cargo de lugarteniente, huyó de la isla (enero de 1447).

Este mismo año se disputan el cargo de lugarteniente Berenguer Unís, Huc de Sant Joan y Bartomeu Fuster que exhibían nombramiento del rey y la reina. Huc de Sant Joan queda como lugarteniente de hecho.

La reina María nombra lugarteniente, en 1447, a Antoni Guillem de Muntanyans, cuñado de Berenguer d'Olms. La reina le ordena investigar cómo logró Huc de sant Joan ser nombrado lugarteniente, dónde juró el cargo y si lo hizo antes o después de jurar las franquicias del reino ${ }^{37}$. El mismo año, fue suspendido temporalmente del cargo de gobernador titular Berenguer d'Olms. La reina nombra al vicecanciller Roderic Falcó como lugarteniente de Mallorca. A finales del mismo año, Alfonso el Magnánimo repone a Berenguer d'Olms como gobernador.

En 1450, el procurador real Joan Albertí ocupa la lugartenencia de Mallorca. Al año siguiente, Olms reasume el cargo y designa a su familiar Jaume Cadell como lugarteniente. Este mismo año 1451, en el curso de la revolta forana, Olms fue cesado definitivamente. En su lugar, la reina María nombró a Arnau de Vilademany como gobernador titular ${ }^{38}$.

Todas las secuencias anteriores responden al criterio establecido por Alfonso el Magnánimo de equilibrar las fuerzas en pugna dentro de un campo de juego establecido por él. Los beneficios de esta política de lo posible eran notorios. Cada cambio

37 En 1447, los bandos se articulaban en torno al procurador real, Joan Albertí, y en torno a Lázaro de Loscos, el mencionado Huc de Sant Joan, Francesc Axaló, antiguo secretario real y Gaspar de Pachs.

38 Las informaciones anteriores proceden de las series del Lletres Reals AH-L.R, Registros 57, $58,59,60,61,62$ ) y las Cartes al Procurador Real (R.P., especialmente los registros 41 y 42 ) del Arxiu del Regne de Mallorca, donde se relata una secuencia prácticamente diaria de los cambios en la ocupación delos cargos. 
del régimen electoral del municipio tenía que venir precedido de una sustanciosa aportación económica. Cuando el rey nombró como lugarteniente, en 1444, a Huc de Sant Joan le exigió una fianza de 500 ducados. Cuando en 1446 el rey designó como procurador real a Joan Albertí le exigió una fianza de 10.000 florines y cuando, dos años antes fue creado el cargo de regente de la procuración real, el rey exigió al nuevo titular Gaspar de Pachs un préstamo de 1.000 ducados $^{39}$.

En 1447 Alfonso el Magnánimo optó finalmente por introducir el siśtema de suerte en la elección de los cargos municipales. La fórmula no era una novedad. En los últimos tiempos del reinado del Ceremonioso se había introducido el sistema, de forma parcial, para la provisión de vacantes. Después el sistema, en su perfil definitivo, aparece aplicado en diferentes localidades en las primeras décadas del siglo XV. Finalmente en Menorca se produjo la implantación de dicho régimen, hacia 1442, por el gobernador Galcerán de Requesens.

Lo que me interesa destacar del régimen de Sort i Sach son los objetivos del rey en torno al nuevo sistema. Es cierto que hay una municipalización de los oficiales reales - batlle y veguer de la ciudad, y veguer foráneo- sometidos al sistema de insaculación, pero ésta se encuentra bajo directo control real. Es el rey quien remite la lista de candidatos a ocupar dichos cargos y el gobernador de Mallorca quien extraerá, cada año, del saco correspondiente el nombre del candidato elegido. Además el nuevo sistema electoral asegura al gobernador una posición central ya que convoca las reuniones plenarias del Consell General, a instancia de los jurados, preside el acto de elección, revisa periódicamente junto con los jurados los sacos y custodia una de las llaves donde se guardan todos los sacos ${ }^{40}$. Como vemos, la posición de los gobernadores salió reforzada al participar como he indicado en la elección-designación de los oficiales reales.

El sistema de Sort i Sach tenía virtualidades evidentes, rompía el esquema de dotar a cada bando con un régimen municipal diferente, como había sido lo usual durante medio siglo. Por ello su carácter integrador resultaba plausible. Por otra parte el espíritu del sistema -en principio deben ser insaculados todos los que reunan aptitudespodía ser soslayado con relativa facilidad, al figurar en las cédulas o redolins sólo los partidarios de uno de los bandos. En suma, el nuevo régimen era apto como sistema de acceso a los cargos, en un ambiente poco proclive a los acuerdos, aunque también resultaba fácilmente pervertible. Acaso por estas razones tuvo tan larga vida hasta el punto de pervivir en la Edad Moderna.

La revolta forana o guerra civil de 1450-1453 y la posterior participación del reino de Mallorca en la guerra civil catalana revisten a la gobernación de un carácter excepcional. Como ya indiqué, en el curso de la revuelta, fue cesado el gobernador titular Bęrenguer d'Olms. En su lugar fue nombrado Arnau de Vilademany, como regent la

39 El rey se comprometió a no relevarlo del cargo mientras viviera Lázaro de Loscos, procurador real, y mientras no le devolviera íntegra y de una sola vez dicha cantidad.

40 A. PONS PASTOR, Constitucions e ordinacions de Mallorca, en el "B.S.A.L." XXIV (19321933), p. 431. 
governació. Al año siguiente, fue enviado a Mallorca, al mando de tropas para reprimir el movimiento campesino, Francesc d'Erill, como capitán y lochtenent general en 10 regne de Mallorques e regent la governació del dit regne. A partir de entonces y hasta 1453 existe una especie de doble gobernación. El rey o la reina María se dirigen a ellos como regents y también como loctinents. También se aplica a Francesc d'Erill el título de virrey y a Vilademany el de regent la governació. A partir de 1454, quedó como único gobernador Francesc d'Erill. Tal situación se explica en virtud de las circunstancias extraordinarias por las que atraviesa el reino de Mallorca en esta época.

Evidentemente, aparte de las consecuencias sociales de la revuelta indicada, cabe destacar un reforzamiento del poder de la monarquía en las islas. Frente a las presiones de los ciudadanos por eliminar las instituciones representativas de los foráneos y su misma representación en el Consel/ General, el monarca restaura dichas organizaciones y asegura la continuidad de la cuota de poder asignada tradicionalmente a los campesinos. El rey es perfectamente consciente de que su eliminación ponía todo el poder municipal en manos de los grupos dominantes ciudadanos., en tanto que su opción restauraba el sistema tradicional de equilibrios y por consiguiente de neutralización mutua. Esto permitía una acción de gobierno menos deudora que de haber subsistido un sólo grupo de presión.

Las acciones militares de Erill y la intervención de Mallorca en la guerra civil catalana provocan intervenciones autoritarias de los gobernadores. En 1474, los jurados se quejaban de que el gobernador decidía por sí mismo la convocatoria o no del plenario del Consell General. A su juicio, cuando la totalidad de los jurados o la mayor parte de ellos le comunicaban su intención de reunir dicho consejo, el gobernador debía proceder inmediatamente a su convocatoria ${ }^{41}$. En 1481, tras múltiples instancias, Fernando el Católico restauró el Consell de Franquesa, aunque bajo los mismos términos de su creación. En efecto, el rey designó dos jurisperitos y ordenó que su composición la siguieran integrando el gobernador, el batlle y los veguers con sus respectivos asesores. Su convocatoria seguía dependiendo del gobernador ${ }^{42}$.

Desde mediados del siglo XV los gobernadores adoptan un doble título funcionarial, el que rubrica su condición de poder delegado y el que afecta a su función. De ahí que Berenguer d'Olms utilice las denominaciones de lochtinent general del molt alt senyor rei e governador del regne de Mallorques. Años después acabará imponiéndose el de lochtinent general, junto con tratamientos ampulosos de magnifich mossèn, molt magnifich mossèn y el de spectable e magnifich y versiones superlativas. También el sueldo de los gobernadores fue incrementado notablemente durante el siglo XV. En 1461, Juan II ordenó aumentar el sueldo del lugarteniente Vidal de Castelldoriz un $13 \%$, situándose en 34.000 sueldos. La coincidencia de este hecho con el inicio de la guerra civil catalana no es mera casualidad.

41 Una protesta en este sentido fue librada al embajador del reino J. Dusay para que la presentara ante el rey (A. PONS PASTOR, Constitucions..., XXV (1934), p. 24.

42 De hecho los dos jurisperitos anteriores, Martí Desbrull y Joan Berard, hacía tiempo que habían fallecido, lo que prueba la inoperancia voluntaria de dicho organismo (ARM, Códice Rosselló Vell, fol. 455 v.). 


\section{LA CURIA DE GOBERNACIÓN: LOS ASESORES}

El origen de los asesores de los lugartenientes se remonta a las tres últimas décadas del siglo XIII, cuando se hace cada vez más perentoria la necesidad de disponer de especialistas en derecho para gestionar la administración judicial. Los lugartenientes debían ser caballeros, que era el requisito fundamental, y eran escogidos en virtud de sus dotes de mando y capacidad militar más que otras consideraciones. Sus conocimientos en derecho, y especialmente del derecho local, eran mínimas. Por estas razones se impone la presencia de expertos, ya que los notarios no podían cumplir esta misión con la idoneidad requerida.

Los primeros jurisperiti que he podido documentar en Mallorca fueron Pere Ros, en 1260, y Pascual de Montagut, en 1262, aunque los documentos no precisan el cargo que ocupan ${ }^{43}$. En 1276, Jaime II de Mallorca juraba los privilegios y franquicias del reino. Se iniciaba un nuevo período histórico, con la dinastía privativa. Entre los testigos del documento aludido se encontraba Arnau Batle, jurisperitus (traducido en la versión catalana como savi en dreff ${ }^{44}$ y en otros documentos de la época dicti domini regis judex. El calificativo de judex, que pervivirá hasta la segunda década del siglo XIV, convivirá con el de asesor. En 1285, ocupaba este cargo, Castelló Sardina, assesor de la Cort de Mayorches, con una remuneración anual de 800 sueldos y tres años después Alfonso III de Aragón utilizaba este mismo término para establecer ciertas incompatibilidades ${ }^{45}$.

La recuperación del reino de Mallorca, por Jaime II, en 1298 provoca una sistematización de la administración real en el archipiélago. Inicialmente, en el mismo año y dado el carácter excepcional de la nueva toma de posesión, el rey designa dos jueces -el mencionado Arnau Batle y Bernat Dalmau- y extiende las asesorías a la lugartenencia de Menorca y a la bailía-lugartenencia de lbiza. Además, en 1299, el rey establece que en las sentencias del gobernador y asesor debían participar ocho prohombres.

A partir de entonces se dota de asesoría a otros cargos - batlle y veguer de la ciudad, y veguer foráneo-, siempre bajo designación real, y por supuesto los numerosos reformadores enviados a Mallorca, en el siglo XIV, se desplazarán con su correspondiente asesor o asesores. En 1327, el infante Felipe envió al reformador Guillem de Pau y a Otón de Caucals legum doctorem. En 1348, Pedro el Ceremonioso designó como reformador a Felip de Boïl y como asesores a Pere de Ciutadilla y Jaçpert de Tragorà ${ }^{46}$.

43 J. VICH y J. MUNTANER, Documenta.., p. 45, doc. $n^{\circ} 35$.

44 E. de K. AGUILO, Franqueses y privilegis., en el «B.S.A.L.»VII (1897-1898), p. 4, doc. nº 1.

45 ARM, Códice Sant Pere, fol. 141 v.).

46 E. de K. AGUILO, Lletres reals, en el «B.S.A.L." XXII (1928-1929), p. 214, doc. nº 30 . El rey les asignó una remuneración diaria de 15 sueldos. 
El carácter cada vez más importante de los asesores - uno de ellos Ramon de Capcir actuó como lugarteniente de Roger de Rovenach en 1337- y su papel cardinal en la responsabilidad de las sentencias, determina su regulación profesional:

- Inmompatibilidades: Por disposición de Alfonso III, en 1288, ningún asesor, en tanto estuviera ocupando el cargo, podría llevar casos particulares, salvo que fueran de época anterior a la ocupación del mismo ${ }^{47}$.

- Requisitos profesionales. Durante el siglo XIII y XIV no existían normas profesionales fijas para los jurisperitos. Podían ser simples bacallarius, licenciatus in legibus o en algún caso legum doctor. En 1333, Guillem Fuster se firma sólo como jurisperito Maioricarum. El mismo año, el asesor del lugarteniente, Arnau Mendoni, se autotitulaba licenciato in legibus, y el mencionado reformador Otón de Caucals era legum doctorem. En 1398, la Pragmática de Huc d’Anglesola estableció los requisitos profesionales de los asesores. Debían jurar haber oído (sic) derecho civil o canónico, durante cinco años, en un Estudio General, poseer libros de derecho y superar un examen ante un tribunal formado por dos juristas, en presencia del gobernador. Años después, en 1519, Carlos I estableció un listón más elevado, al exigir el grado de doctor y haber practicado por lo menos dos años ${ }^{48}$.

— Obligaciones de los asesores: En 1349 el procurador de tribunales Miquel de Montsó alegaba la antigua costumbre de que el asesor de gobernador dictase las sentencias, en lugar público, con el asesoramiento de prohombres. Alfonso el Magnánimo, en 1439, añadió a este precepto el de participar también en las encuestas de los acusados.

La maduración y complejidad crecientes de la sociedad determina la exigencia, cada vez más perentoria de disponer de especialistas en derecho. Esta necesidad, sentida especialmente desde mediados del siglo XIV, chocará, sin embargo con viejas tradiciones jurídicas, como la del consejo de prohombres, y con intereses corporativos como los de los notarios. Como ya adelanté, Jaime II de Mallorca, en 1299, estableció que un consejo de ocho prohombres, entre ellos dos juristas, debían intervenir en las sentencias de los lugartenientes. El carácter innominado del resto de estos prohombres - solían ser notarios y en casos específicos mercaderes, cuando se trataba de asuntos comerciales- se mantuvo durante largo tiempo. Sin embargo, a fines del siglo XIV la presencia de los juristas en asesorías, juicios por delegación, casos judiciales y embajadas era ya incontenible. Los Jurados mismos, en 1390, reconocían que a instancia de las partes litigantes se había introducido la costumbre de que en lugar de convocar prohombres, se llamara a juristas, exigiendo el retorno al viejo sistema. Pocos años después, en 1404, Martín el Humano zanjó definitivamente la cuestión ordenando que en lugar de prohombres, participaran juristas en los procesos y sentencias $^{49}$.

47 ARM, Códice Sant Pere, fol. $141 \mathrm{~V}$.

48 ARM, Códice d'en Abelló, fols. 41 v. y 158 r.

49 ARM, Códice d'en Abelló, fol. 105 v. 
En conexión con ello aparecen en esta época las primeras listas, elaboradas por la gobernación, de jurisperitos ejercientes en Mallorca. Una prueba fehaciente de lo dicho fue una convocatoria realizada por el gobernador Roger de Moncada, en 1408. Con motivo de un conflicto con el obispo de Mallorca, Moncada convocó a veinte jurisperitos, de los cuales por lo menos siete eran doctores. Años después, en 1474, la curia de gobernación llevaba una nómina de los juristas que ejercían en Mallorca. En total figuran teinta y siete individuos (entre expertos en derecho civil y en canónico), de los cuales 27 eran doctores ${ }^{50}$. Podemos contrastar estos datos con informaciones del año 1333, cuando actuaban como asesores del municipio sólo tres savis en dret $^{51}$.

Los asesores se integran en el sistema de bandos que opera en la Mallorca de la primera mitad del siglo XV. Es cierto que el asesor de la gobernación era designado directamente por el rey, pero en perfecto paralelismo con lo que sucedía con este cargo (desdoblado en gobernador y lugarteniente de gobernador) fue más frecuente que el cargo de asesor fuera ocupado por regentes o lugartenientes de asesor, siempre mallorquines, que por titulares de este cargo. Así sucedió con Gabriel Castanyer, que pasa a sustituir al asesor titular Eximén del Poyo, y así lo hace Pere Vanrell, en 1436, como regente del asesor titular Joan de Copons. Una prueba de las redes familiares extendidas por los bandos se produce en 1446. En esta fecha, Joan Albertí fue designado Procurador Real, en sustitución de su enemigo Lázaro de Loscos. El mencionado Albertí presentó su carta de nombramiento al gobernador, ante Bartomeu Albertí, doctor en derecho y lugarteniente del asesor del gobernador, de Arnau Albertí, battle de la ciudad y de Bernat de Juny, veguer de la ciudad. Imposible encontrar una prueba igual de concentración de poder familiar ${ }^{52}$.

Esta situación fue corregida ad beneficium Principis por la Pragmática de Sort $i$ Sach, de 1447, que introdujo la insaculación en el municipio de Mallorca. La normativa de aplicación a la renovación de los asesores fue establecida en la siguiente forma: el rey elaboraría la lista de candidatos aptos para ocupar las tres asesorías - la del batlle de la ciudad, la del veguer de la ciudad y la del veguer de fora-. Sus nombres, inscritos en cédulas (redolins), serían insaculados en tres sacos. Cada año, en presencia del gobernador, serían extraídos dos cédulas de cada saco. Los nombres de los candidatos extraídos de los sacos serían enviados al rey para que designara a uno de ellos como asesor. Esta operación podría ser realizada directamente por el gobernador, por delegación real. En suma, pues, el cargo de asesor pasa a ser anual, y el

50 ARM, Códice Jurisdiccions e Stils, fols. 27 r. y 98 v. Sobre el papel de los juristas en el siglo XV ver A. PLANAS, Los juristas mallorquines en el siglo XV, en "Memòries de l'Academia mallorquina d'Estudis Genealògics». Núm. 7 (1997), pp. 23-59. Sobre las bibliotecas de los juristas, J.N. HILLGARTH, Readers and books in Majorca, 1229-1550, Paris, 1991.

51 Se trata de Guillem Miquel, Guillem Fuzer i Guillem Carbonell, mientras que prestaban servicios a esta institución un total de nueve notarios (P. CATEURA, El regne esvaït, Mallorca 1300-1335, en prensa).

52 ARM, R.P. 42 , fol. 163 v. 
rey tiene un control total sobre todo el sistema de renovación desde la elaboración de las listas de candidatos hasta la designación del elegido, lo que le permite equilibrar fuerzas y controlar los bandos. El asesor del gobernador queda fuera del sistema, siendo designado directamente por el rey siempre entre gentes de fuera de la isla.

\section{LA ESCRIBANÍA DE GOBERNACIÓN}

El primer notario de la curia de la lugartenencia de Mallorca fue Domingo Gil, que figura en 1245 rigiendo la escribanía con el lugarteniente Assalit de Gúdar. Esta situación sólo empezó a cambiar a partir de 1300 con la creciente burocratización fomentada por Jaime II de Mallorca. Es entonces cuando se inician diferentes escribanías, como la del registro (a partir de 1301), de procesos civiles y criminales (desde 1299) $y$ de apelaciones (desde 1334).

A lo largo del siglo XIV se produce una expansión del notariado, en su doble vertiente de actividad privada (se opera en este sentido una especialización en la contratación comercial, incluso por naciones) y de escribanías de las curias. Todo ello generará una copiosa documentación destinada a reglamentar su ejercicio, incompatibilidades, incluso su cuota de poder en los órganos municipales:

- Acceso a la profesión: La documentación de la época reconoce dos sistemas de acceso, bien por una provisión real autorizando su ejercicio, bien a través de un examen realizado en presencia del veguer de la ciudad. Esta fue la normativa establecida en 1345 por Pedro el Ceremonioso, y reiterada por los jurados de la ciudad en $1390^{53}$.

- Incompatibilidades: Estas se aplican a tres áreas de cuestiones. En primer lugar a los notarios que ejercen como procuradores de tribunales, incluso en la curia en la que tienen la escribanía; en segundo lugar, al ejercicio de la función de procurador y la de prohombre y finalmente a los notarios que tienen arrendadas a terceros varias escribanías. Los tres aspectos nos demuestran el grado de expansión corporativa a que habían llegado estos profesionales. Pues bien, ya en 1340, Jaime III de Mallorca estableció que los notarios dedicados también a la procuración de pleitos no podrían actuar como tales en la curia donde trabajaban ${ }^{54}$. Medio siglo más tarde, en 1390 , los jurados ordenaron ya que los notarios no podrían dedicarse a tares de procuración, salvo para asuntos propios. La norma no tenía carácter retroactivo, es decir, los notarios que practicaran desde tiempo antes su doble profesión podrían seguir haciéndolo. A mayor abundamiento, se estableció que desde entonces los notarios, una vez superado su examen ante el veguer, debían jurar ante los Evangelios que no ejercerían

53 A. PONS y PASTOR, Constitucions e Ordinacions..., en el «BSAL»XXIII (1930-1931), p. 209. P. CATEURA BENNASSER, Política y finanzas del reino de Mallorca bajo Pedro $I V$ de Aragón, Palma de mallorca, Instituto de Estudios Baleáricos, 1982, p. 287.

54 La ordenanza real se refiere concretamente a los notarios de la curia del batlle y del veguer de la ciudad. 
también como procuradores ${ }^{55}$. También, en la misma fecha, se les excluyó de ser nominados prohombres, a todos aquellos que ejercían como procuradores. En el caso de que sólo ejercieran su profesión de tabellionatus y resultaran elegidos como prohombres, no podrían volver a ejercer como tales prohombres hasta pasados dos meses.

Finalmente, fue reglamentado el tema del arrendamiento de varias escribanías y de su secuela de absentismo. El tema no era nuevo. Ya en el siglo XIII vemos esta práctica, como algo usual. En 1260, por ejemplo, Pere Ros compraba las escribanías del batlle y del veguer de Mallorca, así como la escribanía de cartas de la antigua porción de Nuño Sans a los herederos del notario Bernat de Lusà. La trasacción fue firmada sin mayores problemas por el infante Jaime, en nombre de Jaime I. Evidentemente, las condiciones del siglo XIII —es decir la escasez de profesionales- no son las del siglo posterior, por consiguiente aquellas prácticas guiadas por la necesidad, se convierten en el siglo XIV en prácticas pura y simplemente monopolísticas y especulativas. En función de estos supuestos, una ordenanza de Pedro IV de Aragón, de 1375, reglamentó que los notarios sólo podrían tener una escribanía y ocuparse de ella personalmente.

- Conservación de los protocolos: En el caso de los notarios que ocupaban escribanías en las curias, su custodia no ofrecía mayores problemas, ya que los registros eran archivados en las respectivas curias. El problema se producía con los notarios dedicados a una actividad privada de su profesión. Aunque la costumbre era transmitir los documentos a otro notario, no siempre las circunstancias personales de estos profesionales y de sus herederos, si los había, aseguraban una conservación y transmisión. Con la finalidad de reglamentar la cuestión fue establecido por los jurados, en 1390 , que los notarios debían entregar los protocolos a individuos de su misma profesión. En caso de haberlos entregado a un particular, el veguer, con el consentimiento de los herederos, ordenaría su entrega a otro notario.

Tal como he explicado, a finales del siglo XIV, se ha producido un fenómeno de delimitación de dos actividades emergentes: la de los juristas y la de los notarios. Los juristas tienen aseguradas las asesorías y actúan en calidad de comisarios, jueces delegados y prohombres, y en cuantas ocasiones son convocados por los oficiales reales para dar un dictamen. Los notarios acaban siendo excluidos de los consejos de prohombres y de la procuración de tribunales pero conservan privilegios muy notorios. En primer lugar, por su misma profesión están perfectamente informados de la coyuntura política -a través de las escribanías de gobernación, de las veguerias y bailíasy en segundo lugar tienen reservado un puesto clave dentro de la administración real, la Procuración Real.

Notarios y jurisperitos exigirán una cuota de poder dentro de la organización municipal, la de formar un estamento aparte de los ya existentes - que en total eran cinco, integrando a caballeros, ciudadanos, mercaderes, menestrales y foráneos 0

55 P.A. SANXO, Antichs privilegis i franqueses..., en el «BSAL»XI (1905-1907), p. 283, doc. no 40 y A. PONS PASTOR, Constitucions e Ordinacions..., en la misma revista, Vol. XXIII, p. 206. 
campesinos-. La propuesta fue rechazada, como ya lo había sido en 1350 la de formar estamento de patrones y marineros. A cambio, se les integró en estamentos ya existentes y que se consideraba que estaban a su nivel. Primero alcanzaron su objetivo los notarios, en 1398, que fueron insertados en el brazo de mercaderes. Después, los jurisperitos, incorporados al brazo de ciudadanos. Dicha inserción ponía a ambas profesiones en condiciones de alcanzar la máxima magistratura municipal, la de los jurados.

Dentro del notariado, las escribanías de gobernación, y también de la procuración real, eran las más apetecidas, al ofrecer perspectivas de mejora profesional y social. Las circunstancias, ya aludidas de la época de Alfonso el Magnánimo, permitieron ascensos sociales y profesionales importantes.

En 1390, Mateu de Loscos era escribano de la procuración real. Seis años después, Martín el Humano lo nombró procurador real. Su hijo, Lázaro de Loscos le sucedió en dicho cargo y a menudo, como ya indiqué, actuó como lugarteniente de gobernador. En 1444, el rey le concedió el señorío de Banyalbufar, con rango de baronía ${ }^{56}$. El recorrido es bien claro y representa el paradigma de lo que en la Mallorca del siglo $\mathrm{XV}$ se consideraba el triunfo social.

Dentro de la escribanías destacaron también otros personajes. Este fue el caso de Francesc Axaló, descendiente el pelaire Antoni Axaló ${ }^{57}$. Francesc entró como notario de la gobernación. Rapidamente se ganó la confianza de Loscos, integrándose en el bando dirigido por este último y en contra del dirigido primero por Pere Descatlar y después por Joan Albertí. Desde por lo menos el año 1435 figura como Secretario real de Alfonso el Magnánimo ${ }^{58}$. A su regreso, en 1447, fue nominado como jurado de la ciudad por el brazo de ciudadanos y en 1452 ya por el de caballeros ${ }^{59}$. Axaló se dedicó a actividades especulativas - figura como arrendador de impuestos municipales-y de crédito.

Un caso similar fue el de Joan Valero. De familia artesana - su padre era espadero ${ }^{60}$ y su abuelo materno pelaire - tanto Joan como su hermano Blai optaron por el oficio de notario. En 1451, en plena revolta forana recibe nombramiento real como escribano de la procuración real. Tres años después, Alfonso el Magnánimo le nombró Secretario real, cargo que siguió ejerciendo con Juan II. A su regreso a Mallorca, en 1467, ya con el título de doctor en leyes, el rey le estableció la escribanía civil de la gobernación de Mallorca junto con los notarios Joan Falcó y Andreu Boix.

56 ARM, R.P. 42 , fol. 52 v.

57 ARM, P.-2466, fol. 47 r.

58 En 1435 consta que Bartomeu Gill, notario, era regentem scribaniam curie gubernationis pro honorabili Francisco Axaloni, Secretario domini regis (ARM, LR 57, fol. 21 r.).

59 En esta fecha se le califica ya de miles, conservando el título de dicti domini regis Secretarius (ARM, E.U 9 , fol. 157 v.).

60 En 1451, Joan Valero, espaserius Maioricarum, como procurador de su hijo del mismo nombre presentaba una carta de nombramiento de este último como escribano in oficio procuracionis regii regni Maioricarum. 


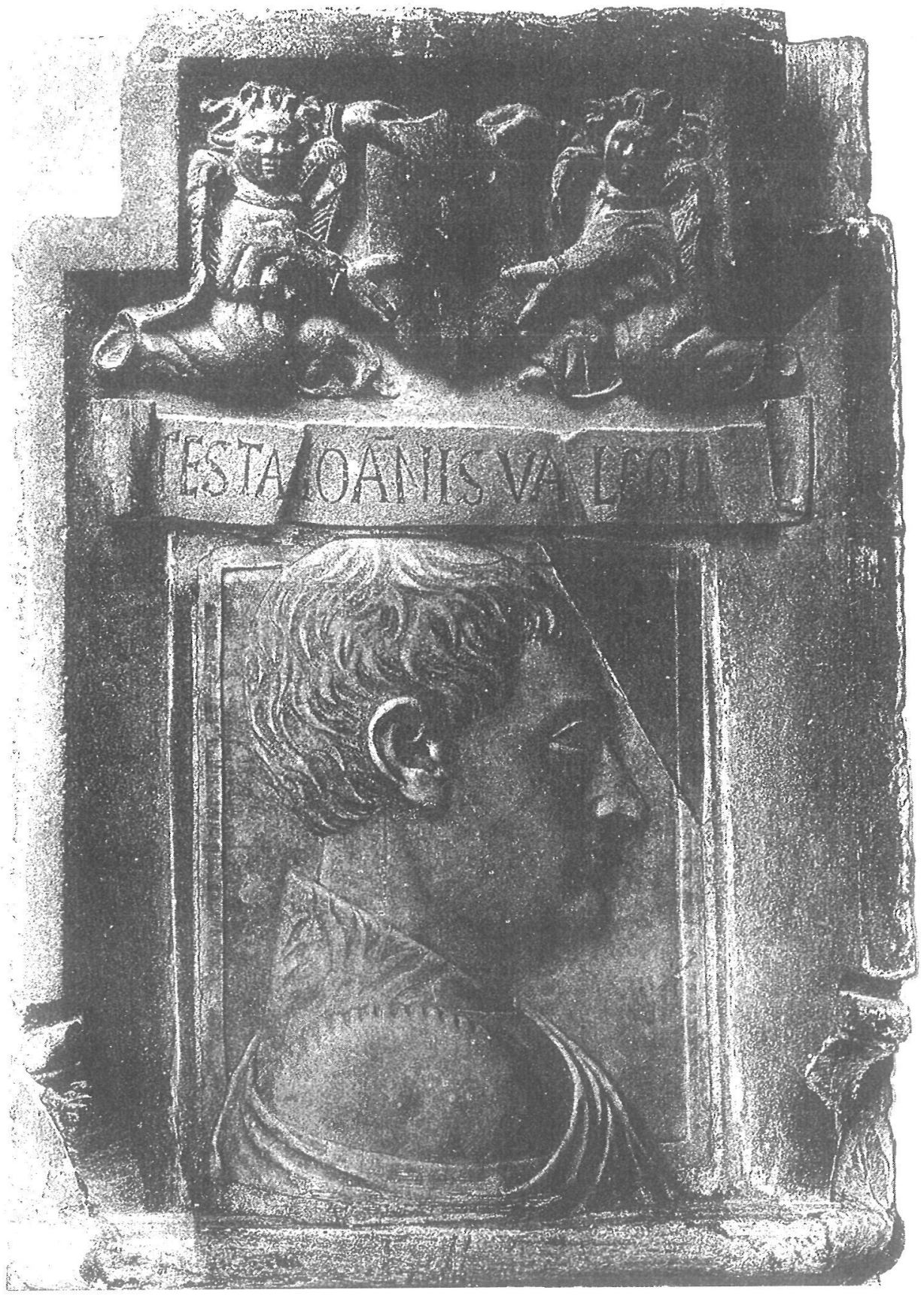

Foto 2. Lápida sepulcral de Joan Valero, secretario de Alfonso el Magnánimo entre 1454 y 1467, despositada en el antiguo convento de Santo Domingo, hoy desaparecido. 
Desde 1468 empezó a ser sorteado para cargos municipales, por el brazo de ciudadanos, experimentando en su larga vida las bondades de la Fortuna y también los reveses de la misma. En el haber se encuentra una larga nómina de ocupación de cargos municipales, dos veces jurado, tres veces conseller del Gran i General Consell y por lo menos una vez ejerció como cónsul de mar y juez de apelaciones de dicho organismo, oidor de cuentas, monedero y almotacén. En 1459 fue remitido por Juan II a Menorca en calidad de visitador para informarse sobre la situación en que se encontraba dicha isla, dividida en bandos ${ }^{61}$.

En su vida privada hubo de todo. Se hizo cargo de su familia-acogió a su padre viudo en su casa, pagó la dote de una hermana para que hiciera un matrimonio con arreglo a su nuevo estado, promovió a un hermano como escribano de la procuración real- $y$ en 1463 fue declarado heredero universal por el mercader acomodado Pere Guialseny, tío político. Del mismo recibió dos viñas y un campo en las cercanías de la ciudad. También una casa dentro de la urbe repleta de muebles, joyas, una colección de armas, además de doce esclavos y un importante lote de operaciones comerciales, entre las que figuraban numerosas comadas no saldadas a favor del difunto. Finalmente, Joan Valero pudo incrementar su biblioteca con la que heredó de Guialseny que era modesta - sólo doce piezas- pero de interés. La integraban libros de agricultura - Ex agro veteri--, recopilaciones normativas - reglamentos de los pelaires-, de religión-un Doctrinal, unas Horas, un libro De les dones religioses-.

De su matrimonio con Simona Sala, hija de un prominente ciudadano, tuvo dos hijos. Uno de ellos, Martín, sacerdote, para el que consiguió del rey un beneficio en la parroquia ciudadana de San Nicolás, y una hija, Anita a la que casó con el destacado mercader Antoni de Verí. En 1480 volvió a torcerse la fortuna. Su hija, recién casada, gravemente enferma, hacía testamento y al año siguiente fallecía su esposa. Simona.

Joan Valero siguió ostentando el cargo de Secretario real -todavía en 1473 el rey se dirige a él como dilecto Secretario-, falleciendo en torno a 1500. De él nos queda un notable retrato, aunque no se ha conservado ninguna de las producciones literarias que compuso, según testimonios documentales de la época.

Como vemos las escribanías de gobernación y de la procuración real se convierten no sólo en centros administrativo-burocráticos, sino también en nudos políticos y en palancas de promoción de los notarios. Durante el siglo XV, la escribanía de gobernación tenía una plantilla de ocho notarios, la procuración real pasó de cuatro a cinco notarios, y la del batlle y del veguer cuatro respectivamente, con lo que las cuatro curias tenían a su disposición un total de 21 profesionales.

61 Estuvo siete meses en dicha isla en tareas de inspección (P. CATEURA: Trabajo y fortuna en el Renacimiento: el caso de Juan Valero, Secretario real, en «América y Mallorca. Del Descubrimiento hasta el siglo XX, Palma de Mallorca, Ajutament de Palma, 1991, pp. 47-52). 


\section{CONCLUSIÓN}

La posición de los lugartenientes-gobernadores a lo largo de los siglos XIII-XV responde básicamente a dos elementos: la dotación jurídica del reino de Mallorca y la evolución de la coyuntura política. La primera cuestión resulta evidente: el reino de Mallorca dispone solamente de un cuerpo de privilegios y franquicias de tipo municipal. Esta situación de puerilitas jurídica fue congelada conscientemente por la monarquía, como presupuesto necesario para un tipo de gobierno sin cortapisas ni intermediaciones no deseadas.

Incluso cuando el reino de Mallorca pasa a depender de una pequeña monarquía, entre 1276 y 1343, su situación a los efectos indicados no sólo no mejorará sino que incluso empeorará. Cuando en 1285, Alfonso III de Aragón ocupe las islas en represalia por el apoyo de Jaime II de Mallorca a los Capetos se entrega a una política de sometimiento y control del municipio. Cuando en 1298, Jaime II de Mallorca recupera el archipiélago, una de sus primeras medidas será la misma instrumentalización municipal. Cuando Pedro IV de Aragón ocupe el reino de Mallorca, en 1343, actuará en la misma forma, designando personalmente a los máximos magistrados municipales. La revuelta antijudía y antioligárquica de 1391 y la revolta forana, de 1450-1453, provocan nuevas intervenciones autoritarias de la Corona.

Todos estos factores nos explican la situación del reino y el fracaso de todas las propuestas que puedan suponer una interlocución más equilibrada entre reino y monarquía. Cuando en 1314 los Jurados consiguen provisionalmente convertir el municipio en una entidad más autónoma, el rey manipula las reivindicaciones de los foráneos o campesinos en contra de la ciudadanos para instituir un nuevo organismo rival, denominado Sindicat de fora. El resultado inmediato fue un debilitamiento de la posición adquirida por los jurados, como portavoces del reino e interlocutores exclusivos de la monarquía. Cuando los jurados proponen la creación de un organismo específico que vele por la integridad de los privilegios y franquicias del reino, el rey Martín el Humano pondrá el nuevo organismo en manos del gobernador.

Sólo algunas circunstancias extraordinarias permiten vislumbrar algún rasgo de confrontación, que demuestra cierta identidad o conciencia de la personalidad de reino. Cuando en 1469, Juan II, en plena guerra civil catalana, decide convocar a los representantes del reino a Cortes, el Consell General decide convertirse en asamblea soberana. Envía un representante a las mencionadas Cortes, pero le hurta la potestad de otorgar un subsidio, en nombre del reino.Las instrucciones que recibió el representante fueron claras. Cuando en las sesiones se tratara de negociar un subsidio a favor de la Corona, debería evacuar consultas al Consell General. Dichas consultas fueron realizadas efectivamente y en tanto duraron las sesiones de Cortes, los Jurados y el Consell General se negaron, en redondo, a conceder cualquier tipo de ayuda a la Corona. Sólo una vez clausuradas aquéllas, el Consell Genera/ votó una cantidad a favor del rey. Quedó entonces claramente establecido que el Consell General no reconocía un organismo superior y por consiguiente que él mismo disponía de la soberanía en cuanto a la concesión o no de ayuda financiera. Pero una actitud de este 
tipo fue sólo flor de un día y debe enmarcarse en un contexto de debilidad coyuntural de la monarquía.

Un entorno sociológico y político como el indicado facilitó sin duda la actividad de los gobernadores. Su gestión, al no estar interferida por la legislación del reino, se limitaba a buscar la fórmula y el momento de poder presionar al municipio, guardando ciertos equilibrios entre ciudadanos y foráneos. Si fallaban estas operaciones, siempre se podía recurrir, como hizo Olfo de Prócida, a encerrar a los consellers del Consell General en la sala de sesiones hasta que tomaran una decisión, intimidándolos con la construcción de un patíbulo. Eran medidas in extremis pero ilustradoras del talante de los gobernadores.

Pedro IV de Aragón estableció que los gobernadores de Mallorca no podrían ser originarios del Rosellón ni de Aragón. Este mandato se explicaba en función de dos supuestos: la catalanización del reino, cosa que en la isla nadie discutía, y el de evitar cualquier tipo de nexo entre los territorios de la antigua Corona de Mallorca. Esta ordenanza, dictada por las circunstancias, era y se convirtió con el tiempo en una autolimitación de la monarquía. Por ello, a partir de Fernando I, se escogerán gobernadores de origen valenciano - técnicamente, según la mencionada ordenanza de Pedro V, éstos eran catalanes-y del Rosellón - también catalanes-. Se trataba, sin duda, de una pequeña vendetta de los primeros Trastámaras por el comportamiento de los compromisarios catalanes en Caspe.

Sin embargo, a partir de 1425, Alfonso el Magnánimo opta por un cambio de estrategia respecto a los gobernadores de la isla. Designa al rosellonés Berenguer d'Olms, como gobernador titular, pero en realidad quienes hacen sus veces son los lugartenientes, en su mayor parte de origen mallorquín. El predominio coyuntural de una u otra facción será la guía segura para encargar la lugartenencia a un jefe de partido. Así sucederá con Lázaro de Loscos, procurador real y lugarteniente en muchas ocasiones durante este período, con Huc de Sant Joan y con Joan Albertí, que le sucedió en el cargo. Sin duda, en la mente de Alfonso el Magnánimo pesaban razones de oportunidad y de eficacia. Un lugarteniente, jefe de partido, que controlaba un organismo financiero como la procuración real, y, a través de su partido, el municipio, facilitaba la tarea de interlocución y especialmente el drenaje económico a favor de las empresas de la monarquía.

Como los nombramientos de lugarteniente eran a precario, el rey siempre podía revisar su nombramiento a favor de otra facción o partido. La actitud del rey es por consiguiente la de maniobrar y aprovecharse de las luchas de partidos, no la de establecer quienes eran los buenos y quienes los malos, quienes tenían razón y quienes no. Esta actitud no fue compartida por la reina María, que tuvo encomendados los asuntos de Mallorca durante largo tiempo. Cuando en 1447, la situación política del reino se desbordó - tres jefes de fación se disputan la lugartenencia y algunos miembros de las mismas se encontraban en prisión-el rey le retiró la gestión de los asuntos de Mallorca. Pero tampoco Alfonso el Magnánimo supo encontrar una fórmula adecuada al momento. En 1450 estallaba la revolta forana, que abría una nueva etapa de la historia del archipiélago. 
La segunda mitad del siglo XV está presidida por las secuelas de dicha revolta y sobre todo por problemáticas externas —la guerra civil catalana de 1462-1472-que congelan la solución de los problemas de las islas. Estas vivieron en una situación de excepción hasta 1458, cuando fue cesado Francesc d'Erill, encargado de reprimir el movimiento campesino. Cuatro años después estallaba la guerra civil catalana lo que impuso al reino de Mallorca un sistema de prioridades, económicas y militares. Lo externo se impone a la problemática interna. Incluso finalizada la mencionada guerra, siguen determinadas actitudes de los gobernadores. Estos se había irrogado la potestad de convocar o no a los miembros del Consell General, cuando el sistema usual era que los jurados, o la mayor parte de los mismos, justificaban al gobernador la convocatoria de dicha asamblea, y este último se limitaba a tramitarla sin más expedientes.

Cuando finaliza la Edad Media el reino de Mallorca ofrece una aspecto paradógico, por cuanto es políticamente dócil - muy en la línea del nuevo estilo de gobierno de las monarquías de la época-y socialmente convulso, como se encargará de demostrar la Germania. 